\title{
Milling Activation for the Solvent-Free Synthesis of Zeolites. A Practical Guide
}

\author{
Agnieszka Kornas (D), Joanna E. Olszówka, Petr Klein and Veronika Pashkova *D \\ J. Heyrovsky Institute of Physical Chemistry, Czech Academy of Sciences, Dolejškova 2155/3, \\ 18223 Prague 8, Czech Republic; agnieszka.kornas@jh-inst.cas.cz (A.K.); joanna.olszowka@jh-inst.cas.cz (J.E.O.); \\ petr.klein@jh-inst.cas.cz (P.K.) \\ * Correspondence: veronika.pashkova@jh-inst.cas.cz
}

check for

updates

Citation: Kornas, A.; Olszówka, J.E.; Klein, P.; Pashkova, V. Milling Activation for the Solvent-Free Synthesis of Zeolites. A Practical

Guide. Catalysts 2021, 11, 246.

https://doi.org/10.3390/catal11020246

Academic Editor: Roman Bulánek

Received: 22 January 2021

Accepted: 9 February 2021

Published: 12 February 2021

Publisher's Note: MDPI stays neutral with regard to jurisdictional claims in published maps and institutional affiliations.

Copyright: (c) 2021 by the authors. Licensee MDPI, Basel, Switzerland. This article is an open access article distributed under the terms and conditions of the Creative Commons Attribution (CC BY) license (https:/ / creativecommons.org/licenses/by/ $4.0 /)$.

\begin{abstract}
The paramount challenge of current chemical technology, including catalysis, is meeting the ecological sustainability requirements. The feasible production of zeolites is crucial because they constitute the principal group of heterogeneous catalysts. However, current zeolite manufacturing via hydrothermal synthesis is connected with considerable consumption of water resources, generation of wastewater, and significant equipment costs. Solvent-free strategies have attracted great attention as high-yielding methods for sustainable synthesis, particularly beneficial in terms of water consumption minimization and an outstanding increase in production due to the efficient use of synthesis space capacity. So far, the solvent-free preparation of numerous zeolite materials has been performed with the preceding grinding of reagents in a mortar. The proposed article describes recent advances in the application of automatized milling instead of manual work. Pretreatment automatization makes the entire process well-controlled, less sensitive to human factors, and is significantly more relevant to industrial scale-up. Moreover, the automatized milling activation unlocks opportunities for solvent-free synthesis from a broader range of common reagents, where the manual treatment is not efficient. Possibilities and limitations of the milling methods are discussed on the basis of a comprehensive analysis of parameter optimization, activation mechanisms, and applicability of common reagents used for zeolite production.
\end{abstract}

Keywords: zeolites; mechanochemistry; automatized milling; solvent-free synthesis; sustainability; reproducibility

\section{Introduction}

Zeolites are microporous aluminosilicates with a crystal framework consisting of silica and alumina tetrahedrons creating a system of linked channels and cavities. Due to the fact that the isomorphic substitution of silica by aluminum gives the framework a negative charge, positive counter-species in the form of protons or other cations are also present in the zeolite channel system, giving rise to Brønsted and Lewis acidity and/or redox activity. The most remarkable property of zeolites is the shape selectivity, which means different ions and molecules can enter or leave the framework strictly depending on the size and shape of the channels. This, together with the presence of active sites, makes zeolites excellent materials for application in catalysis. Each zeolite structure has a unique crystal topology reflected in its tunable channel/cavity system and tunable chemical composition, and therefore, its own set of sorption and catalytic properties.

The role of zeolites in technological development is difficult to overestimate. Currently, worldwide consumption of synthetic zeolites is approximated at 1.7-2.0 million metric tons per year. While most of this amount is used for detergents and gas separation and purification, the costliest zeolite manufacturing processes are connected with their application as industrial catalysts.

The excellent catalytic performance of zeolites together with the possibility of tuning their catalytic properties, i.e., choice of the type of shape-selective microporous structure 
combined with tunable chemical composition, has led to large-scale implementation in the petroleum industry [1-3]. The prevalent industrial applications of zeolites include: fluid catalytic cracking (FCC) of heavy petroleum, isomerization for octane number enhancement of light gasoline, $\mathrm{N}_{2} \mathrm{O}$ abatement and utilization, abatement of $\mathrm{NO}_{\mathrm{x}}$ from diesel exhausts, hydrocracking of heavy petroleum distillates, and isomerization of xylenes [3,4]. Moreover, zeolites have a high potential in emerging environmental and fine chemistry applications, such as utilization of methane, conversion of biomass and $\mathrm{CO}_{2}$ deployment [4].

The constant demand of the industry for more efficient zeolitic catalysts was so great that it drove the research to the discovery of more than 250 zeolite structures [5].

Traditional manufacturing of zeolites is carried out by hydrothermal synthesis. This process includes high-temperature treatment of reagents in sealed autoclaves in water medium under autogenous pressure [6], resembling the geological conditions under which natural zeolites have been formed. However, this approach has some serious drawbacks. First of all, the use of solvent leads to considerable consumption of water resources, requires filtration, and generates wastewater. Secondly, the hydrothermal process is associated with costs of high-pressure equipment, and expenditure of thermal energy, due to the necessity of heating the amount of solvent.

The development of new zeolite-based catalysts with uniquely high activity, selectivity, and stability for the new generation of industrial catalytic processes results in enormous demands in the onward simplification of the zeolite synthesis procedures. There is a strong pressure to meet the stringent regulations of zeolite production sustainability (i.e., economic use of water, material- and cost-efficiency) while keeping the synthesis process feasible and applying cheap and safe reagents $[7,8]$. In view of this, the investigations in the field of sustainable innovative solutions for zeolite synthesis are directed towards: avoiding organic components in the synthesis recipes, elimination of synthesis steps, shortening the synthesis time, or increasing the space yield of the product by using concentrated synthesis mixtures (with a minimized contribution of a solvent).

Amongst the novel approaches to chemical synthesis, solvent-free strategies combined with mechanochemical activation have attracted great attention recently as a sustainable pathway called Chemistry $2.0[9,10]$. Recent developments in mechanochemical synthesis performed by grinding or milling without a need for solvent mediation include the preparation of organic, inorganic, and complex advanced materials, most notably metal-organic frameworks (MOFs) $[9,11]$.

Moreover, it was demonstrated that the solvent-free approach, supported by preceding grinding in the mortar, could be successfully used for the preparation of numerous zeolite structures, helping to overcome serious drawbacks connected with the traditional hydrothermal route (detailed above). A summary of rapid advances in the solvent-free synthesis of zeolites can be found in a review by Wu et al. [12]. The authors of the mentioned review highlighted that scaling up the developed procedures represents a significant challenge, and emphasized the demand for further exploration of this fascinating research area with possibilities to open new aspects of the mechanochemical activation processes and their large-scale implementation in the near future.

To address the problems connected with manual work during the reagent mixing in a mortar (e.g., poor reproducibility, small scale of the process), automatization of that process should be introduced. In the authors' opinion, the studies on automatized milling activation for the solvent-free processes, instead of manual grinding, constitute the necessary step towards industrial solvent-free zeolite production.

The present review describes recent advances in the application of automatized milling instead of manual work. Additionally, it is intended as a practical guide for the implementation of automatized reagent pretreatment in zeolite solvent-free production and includes how-to recommendations on milling equipment choice, parameters optimization, and reagent suitability, based on the most recent literature reports and the authors' practical experience. 


\subsection{Classical Hydrothermal Synthesis}

In the present section, a brief background to the standard zeolite synthesis is provided, which is necessary to understand the prerequisite conditions and physicochemical processes accompanying aluminosilicate crystallization.

Preparation of the starting gel for classical hydrothermal zeolite synthesis requires $\mathrm{Si}$ and Al sources, cationic or organic structure directing agent (SDA), mineralizing agent, and the solvent (water).

The traditional synthesis procedure can be briefly summarized in the following steps [6]:

(1) Si and $\mathrm{Al}$ sources are mixed in a water solvent with a mineralizing agent, usually an inorganic base (e.g., alkali hydroxide);

(2) Organic structure-directing agent (OSDA) is added eventually;

(3) The obtained mixture is optionally aged for times ranging from a few minutes to a few days until formation of synthesis gel;

(4) The ready gel is transferred to autoclaves;

(5) The autoclaves are sealed and heated to create the hydrothermal conditions;

(6) The agitation is applied optionally (bearing in mind that this parameter is significant, and altering the agitation conditions may result in competing crystalline phases);

(7) Energy of heating at the hydrothermal conditions is consumed for the creation of $\mathrm{Si}-\mathrm{O}-\mathrm{Si}$ and $\mathrm{Si}-\mathrm{O}-\mathrm{Al}$ bonds;

(8) Gradual growth of crystalline zeolite takes place during synthesis times ranging from a few hours to a few days (depending on the structure and chemical composition);

(9) Autoclaves are cooled down and opened;

(10) The zeolite product is recovered by filtration, washed and dried;

(11) Where organic components were used at step (2), they are removed (burned) by post-synthetic thermal treatment.

Figure 1 shows the principle of classical hydrothermal zeolite synthesis.

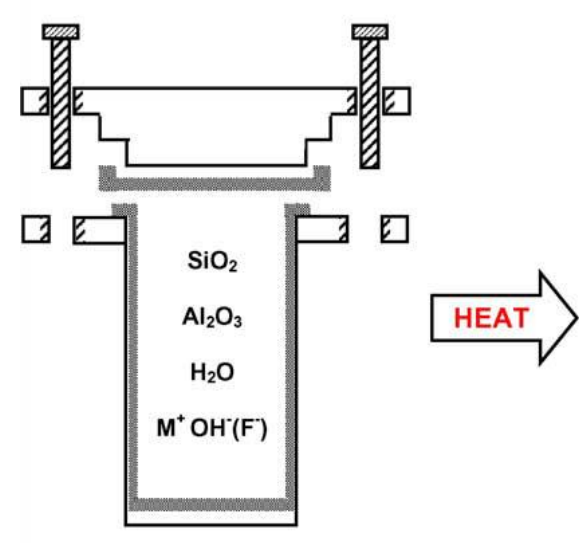

$$
\mathrm{Si}-\mathrm{O}, \mathrm{Al}-\mathrm{O} \text { bonds }
$$
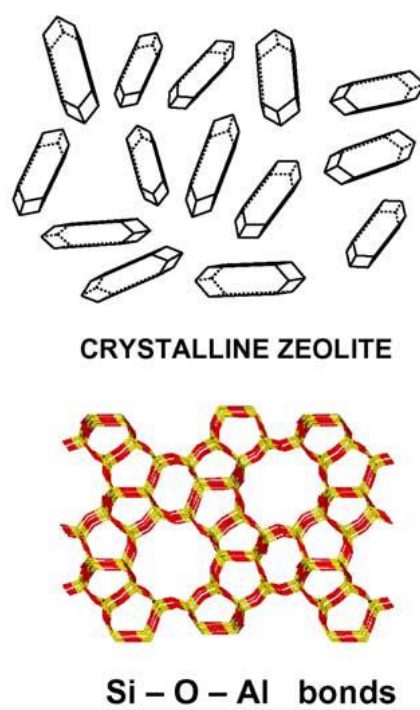

Figure 1. Zeolite synthesis principle. (Reprinted with permission from [6], Copyright: 2005, Elsevier).

\subsubsection{T-Atoms Sources}

Zeolite structures are oxides composed of corner-sharing $\mathrm{TO}_{4}$ tetrahedra, where $\mathrm{T}$ atoms are $\mathrm{Al}$ or $\mathrm{Si}$. Since the discovery that other atoms could be isomorphically incorporated to the zeolite framework [13] and play the role of T-atoms, this definition has been expanded to include T-atoms other than $\mathrm{Si}$ and $\mathrm{Al}$ in the framework (e.g., P, Be, Ge, Ga, Fe, Ti, etc.). 
The most commonly used Si sources are colloidal solutions (e.g., Ludox), amorphous silica (fumed silica, precipitated silica), tetraethyl orthosilicate (TEOS), sodium silicate solutions, silicic acid, and a variety of silica gel grades. Aluminum is usually added in the form of salts (sodium aluminate, aluminum nitrate, etc.), aluminum powder or foil, or in an organic form (e.g., aluminum isopropoxide, butoxide). In some cases, synthetic aluminosilicates, natural minerals (clays), or other zeolites may be used as parent materials [14]. In case the desired structure is to be isomorphically substituted, a source of the heteroatoms (other T-atoms) must be added to the synthesis mixture too (or instead of $\mathrm{Si}$ and $\mathrm{Al}$ sources).

Various T-atoms sources, which are different in pre-ordering, give rise to different rapidity of dissolution and formation of anions, influencing crystal nucleation and growth kinetics, resulting foremost in different synthesis speed, and in the possibility of controlling crystal size and morphology $[6,15]$. Moreover, the choice of the sources depends on synthesis conditions and gel composition. Due to the specific molar composition of the zeolite (the so-called "Si/ Al window" that is possible to have in the obtained structure), every structure has a preferential stoichiometric ratio of components. However, the resulting $\mathrm{Si} / \mathrm{Al}$ in the obtained product does not always correspond to the molar composition of the synthesis gel.

\subsubsection{Structure Directing Agent (SDA) and Mineralizing Agent}

The role of the structure directing agent in zeolite synthesis is to govern the formation of the desirable aluminosilicate network as well as to destabilize the formation of byphases. Usually, organic (e.g., quaternary alkylammonium species) and inorganic cations (e.g., sodium) are used as SDAs. In some cases, neutral molecules (amines, ethers, alcohols) or salts function as SDAs. The process of the structure direction is based on the organization of the silica and alumina species around the molecules of SDA. Coulombic and van der Waals interactions between the silica or alumina species and the SDA molecule play the most important role in the structure directing mechanism. In case the obtained zeolite contains organic moiety, occluded in its cages and channels, it is required to perform postsynthetic high-temperature treatment (calcination) in order to burn out organic compounds. From the point of view of sustainability, the development of synthetic approaches free from organic structure directing agents (OSDA-free) is very favorable, because those components are usually costly, toxic, and require post-synthetic removal.

Generally, zeolite synthesis is carried out in basic conditions $\left(\mathrm{OH}^{-}\right.$anions must be added), which is crucial for dissolution of the $\mathrm{Si}$ and $\mathrm{Al}$ sources and subsequent formation of the aluminosilicate species [6]. To ensure a high $\mathrm{pH}$, the hydroxides (ammonium, sodium, potassium, or quaternary alkylammonium) are used. The role of alkali and quaternary alkylammonium hydroxides as the SDAs usually overlaps with their function as mineralizing agents, due to their basic $\mathrm{pH}$. Syntheses of zeolites in acidic fluoride medium is also possible, as this medium also dissolves silica species $[16,17]$.

\subsubsection{Role of Water in Zeolite Crystallization}

The water serves as a reaction medium for dissolved $\mathrm{Si}$ and $\mathrm{Al}$ species, and dilutes SDA and mineralizing agent. At high synthesis temperature in a sealed autoclave, the water turns into vapor, providing hydrothermal pressure. For a long time, it had been taken as an axiom that formation of the zeolite framework is possible only in a significant amount of the water medium, and moreover, a sufficient amount of water is needed for the generation of high autogenic pressure. Starting from the 1990s, the dry gel conversion (DGC) method has been applied, demonstrating that at least a major portion of the solvent is not necessary for successful zeolite formation. However, the presence of water vapor or the use of water during the preparation of the "dry gel" still was considered necessary. In contrast to DGC, the solvent-free approach, of which the first application dates back to 2012 [18], does not use added solvent for preparation of the synthesis mixture or in the synthesis process. Nevertheless, in the solvent-free route, the presence of water is crucial 
for silica depolymerization. During the silica and alumina condensation, water molecules are released; therefore, the crucial role of water in the solvent-free process could be described as a "catalyst" of the zeolite network formation [12]. A detailed discussion of advances in zeolite synthesis in the dry phase, both DGC and solvent-free, is provided in the following sections.

\subsection{Synthesis with Minimized Amount of Water}

\subsubsection{Dry Gel Conversion}

The dry gel conversion (DGC) method has opened the way for studies of zeolite crystallization occurring in a dry phase and showed that a major portion of the solvent can be successfully removed. Since its discovery, the DGC approach was found to be effective for the preparation of zeolite powders [19,20], zeolite membranes [21,22], and hierarchical micro-mesoporous materials [23,24]. During synthesis, the water transport to the dry gel occurs through a vapor phase (this process is called the steam-assisted conversion or SAC) [24-26]. Usually, for this purpose a separate water vessel is installed in the autoclave space. Even though the crystallization process is performed in the dry phase, this method often requires complex additional steps for the dry gel preparation, e.g., the prior homogenization of reagents in the solvent (water or alcohol), resulting in solvent consumption. Moreover, this method might be connected with additional equipment costs for the generation of water vapor. In the case of DGC, the mechanochemical activation by milling or grinding is not applied, instead the reagents are usually mixed in a solvent and dried before the synthesis.

\subsubsection{Solvent-Free Synthesis}

In contrast to dry gel conversion, the solvent-free route does not apply solvent during the preparation of the synthesis mixture, or during crystallization. Even so, as it was shown in the works of Xiao $[12,18,27,28]$ the presence of water is crucial for the silica source depolymerization preceding the crystallization. Comprehensive discussion of the solvent-free crystallization mechanism and the role of water in the formation of zeolite can be found in Ref. [12]. Fundamental studies on zeolite crystallization have shown that formation of the aluminosilicate framework is also possible in a completely anhydrous system using the fluoride route [29]. However, due to the toxicity of the fluoride medium, this approach does not have potential as a sustainable way for zeolite preparation on a significant scale.

So far, the solvent-free syntheses of zeolite structures MFI, MTN, SOD, MOR, BEA, FAU, EUO, TON, and CHA by grinding activation have been performed [18,30-32]. The solvent-free approach was applied to obtain hierarchical ZSM-5 for the methanol to gasoline (MTG) conversion [33]. Moreover, by the mechanochemical solvent-free method the introduction of heteroatoms into the zeolite network was facilitated (titanium: TS-1 with MFI and Ti-Beta with BEA topologies [34]; and phosphorus: a range of SAPO and APO materials of different topologies [27]).

Most commonly, the necessary small amount of water in the solvent-free process comes from the raw materials (water of crystallization in aluminum salts or water of hydration in silica sources), hence no more solvent is added. The absence of the liquid medium requires effective reagent mixing/grinding in the dry phase usually performed manually in a mortar. The recent advances in the solvent-free synthesis of zeolites supported by manual grinding in a mortar are summarized in [12]. The above-mentioned work and other reports $[9,10]$ highlighted that in the case of manual grinding a scale-up of the treatment for industrial catalyst production might be difficult to achieve. The main reason is the human factor, intrinsically connected with problematic reproducibility of manual work, and the limited quantity of the reagents that can be treated in a laboratory mortar. The automatization of the mechanochemical treatment with its reproducible set of optimized parameters presents a suitable solution. 


\subsection{Mechanochemically Assisted Synthesis}

Rediscovery of mechanochemistry, inspired by the demand for a more materialefficient and safer approach to chemical transformations, and supported, in particular, by the development of experimental methods for the elucidation of corresponding reaction mechanisms, has led to rapid advances in solvent-free syntheses of various compounds performed by grinding or milling. Among the mechanochemical techniques, grinding in a mortar is the cheapest and most accessible. Still, as highlighted above, it is strictly connected with human factors, limited reproducibility, and scalability. The automatized milling techniques (for example, planetary and ball or shaker mills, generating mechanical energy by the movement of milling balls in a bowl or jar) apply reproducible parameters, and are significantly more relevant to industrial scale-up. On the other hand, the automatized approach requires an initial investment into the equipment and numerous trial-and-error experiments to optimize the milling parameters. Automatized milling allows the adjustment of the applied mechanical energy by variation of the milling rotation speed, treatment time, and ball-to-powder ratio (BPR). Increased intensity of the milling, however, leads to increased energy consumption, excessive heating of the system due to friction, consequent milling parts destruction, and sample contamination by the material originating from the milling balls and bowl $[9,35]$. In some cases, to gain more control over the milling, it is advised to add a small amount of liquid in order to reduce the friction. Liquid-assisted grinding (LAG) is characterized by a quantitative coefficient $\eta$, equal to the ratio of the volume of liquid to the weight of the reactant mixture. For the neat or dry grinding (milling) process $\eta=0$, and for the LAG process the $\eta$ value lies in a range below $1 \mu \mathrm{L} / \mathrm{mg}[9,11]$.

In the past few years automatic milling methods have been applied in zeolite synthesis, in particular, in the procedure when zeolite crystals are milled into nanopowder and further recrystallized into a material with the same topology, but higher crystallinity combined with nanosized features originating from the milling treatment. This approach was used for modification of zeolite A (LTA topology) [36] and zeolite ZSM-23 (MTT topology) [37]. The recent review by Liu et al. shows examples of the implementation of milling techniques in the ultrafast synthesis of multiple zeolite structures and MOFs [38]. Mechanochemical treatment was applied for the introduction of Sn heteroatom into BEA [39] and MFI [40] structures. Moreover, Ref. [39] highlights the increased effectivity of automatized milling compared to manual grinding for the preparation of Sn-substituted zeolite [41].

The main focus of the present review is to show the ways in which automatized mechanochemical activation of reagents can be used for solvent-free synthesis of zeolites, demonstrating it to be a more efficient alternative to manual grinding. In particular, cases where the milling activation was effective for crystallization of reagent systems, whereas manual grinding did not provide sufficient energy input, will be presented. Additionally, milling parameters adjustment, selection of reagents suitable for high-energy milling treatment, and elucidation of mechanochemical activation mechanism will be discussed.

\section{Milling Activation for the Solvent-Free Synthesis of Zeolites}

The reports summarized in the present review appeared during the past three years, showing that the replacement of manual grinding by automatized processes is an ongoing trend in the field of zeolite solvent-free synthesis.

Recent accounts of the solvent-free zeolite synthesis with the implementation of automatized pretreatment of reagents include preparation of MOR (mordenite) [42-44], MFI (ZSM-5) [44,45], and CHA (both high-alumina chabazite [46] and it's high-silica analogue SSZ-13 [47]). The summary of data on automatized milling applied in solventfree zeolite synthesis, including technical details, is presented in Table 1.

The work of Gao et al. [42] applied automatized pretreatment to the solvent-free laboratory production of a large amount of mordenite ( $650 \mathrm{~g}$ out of $1 \mathrm{~L}$ autoclave), demonstrating a manifold increase in product/synthesis mixture yield due to the absence of water, together with a significant advance in scaling up the solvent-free process owing to the automatization of grinding pretreatment. 
Table 1. Summary of reports on solvent-free syntheses of zeolites with automatized pretreatment.

\begin{tabular}{|c|c|c|c|c|c|c|c|}
\hline Structure & Ref. & Sources $\mathrm{Si}, \mathrm{Al}$, SDA & Type of Activation Applied & Time, Speed & Si/Al (mix; prod) & Source of Water & $\begin{array}{c}\text { Syn-Thesis } \\
\text { Time, h }\end{array}$ \\
\hline MOR & {$[42]$} & $\begin{array}{l}\text { Hydrated sodium silicate, } \\
\text { silicic acid, boehmite (Al) }\end{array}$ & Automatized grinding (no details) & $\begin{array}{l}20-60 \text { s, no data } \\
\text { for speed }\end{array}$ & $\begin{array}{c}3.75-12.5 \text { in the } \\
\text { starting mixture, } \\
\text { no data for the product }\end{array}$ & $\begin{array}{c}\text { Water of } \\
\text { crystallization }\end{array}$ & 24 \\
\hline MOR & [43] & $\begin{array}{l}\text { Precipitated silica, } \\
\text { sodium aluminate }\end{array}$ & $\begin{array}{c}\text { Planetary milling, } \\
\text { (Fritsch Pulverisette 6; corundum } 250 \mathrm{~mL} \\
\text { bowl and balls ( } 45 \text { pc of } 15 \mathrm{~mm} \text { diameter) } \\
\text { liquid assisted and dry }\end{array}$ & $20 \mathrm{~min}$ at $400 \mathrm{rpm}$ & $15 ; 6$ & $\begin{array}{l}\text { Water added to } \\
\text { autoclaves or milling } \\
\text { bowl }\end{array}$ & 24 \\
\hline $\mathrm{CHA}$ & {$[47]$} & $\begin{array}{l}\text { FAU zeolite (both } \mathrm{Si}, \mathrm{Al}) \text {, } \\
\mathrm{KOH}\end{array}$ & $\begin{array}{c}\text { Planetary milling (Fritsch Pulverisette 6; } \\
250 \mathrm{~mL} \text { ceramic } \\
\text { pot containing } 5 \text { YTZ balls) }\end{array}$ & $1 \mathrm{~h}$ at $150 \mathrm{rpm}$ & $\begin{array}{l}2.8 \text { in parent FAU; } 2.6 \text { in } \\
\text { the product }\end{array}$ & SAC method & $18-48$ \\
\hline $\begin{array}{c}\text { CHA } \\
\text { (SSZ-13) }\end{array}$ & {$[46]$} & $\begin{array}{c}\text { Precipitated silica, } \\
\text { fumed silica, commercial } \\
\text { SDA solution TMAdOH, } \\
\text { Al hydroxide }\end{array}$ & $\begin{array}{c}\text { Planetary milling, } \\
\text { (Fritsch PULVERISETTE } 6 \text { corundum } \\
250 \mathrm{~mL} \text { bowl and balls ( } 45 \mathrm{pc} \text { of } \\
15 \mathrm{~mm} \text { diameter) } \\
\text { liquid assisted }\end{array}$ & $20 \mathrm{~min}$ at $400 \mathrm{rpm}$ & $\begin{array}{l}10 \text { mix; } 7-10 \text { product } \\
\text { depending on Si source }\end{array}$ & $\begin{array}{l}\text { Water from SDA } \\
\text { solution }\end{array}$ & $96-144$ \\
\hline MOR & \multirow[b]{2}{*}{ [44] } & \multirow{2}{*}{$\begin{array}{l}\text { Hydrated sodium silicate; } \\
\text { silica gel; aluminum } \\
\text { sulphate; } \mathrm{NaOH}\end{array}$} & \multirow{2}{*}{$\begin{array}{l}\text { Ball milling (Form-Tech Scientific } \\
\text { FTS 1000, } 10 \mathrm{~mm} \mathrm{ZrO}_{2} \text { balls) }\end{array}$} & \multirow{2}{*}{$\begin{array}{l}25,50 \mathrm{~min} \text { at } \\
1400 \mathrm{rpm}\end{array}$} & 15 mix; 6-7 prod & \multirow{2}{*}{$\begin{array}{c}\text { Water of } \\
\text { crystallization }\end{array}$} & 48 \\
\hline ZSM-5 & & & & & $\begin{array}{l}15,20 \text { mix; } \\
13-15 \text { prod }\end{array}$ & & 48 \\
\hline
\end{tabular}


Other important studies reported by Nada et al. were focused on the elucidation of reaction pathways occurring in the mixture milled manually and by a ball mill, leading to the successful crystallization of ZSM-5 [45] and mordenite [44,45]. These results showed that the transformations occurring during the pretreatment are of a chemical nature, not limited to physical mixing or particle size reduction. Moreover, the increased effectivity of automatized milling in comparison to manual treatment was observed for the studied systems in Ref. [45].

Further examples of the higher efficiency of automatized activation in comparison to manual grinding were demonstrated by Pashkova et al. Application of planetary milling has led to successful crystallization of SSZ-13 [46] and mordenite [43] zeolites in the systems based on precipitated silica, for which the manual treatment was not effective (i.e., respective syntheses with the same chemical composition resulted in amorphous products).

Another advantage of the efficient milling activation is that it can be combined with other synthesis procedures, like the steam-assisted conversion (SAC) method (see Section 1.2.1), as reported by Miyagawa et al. [47]. The proposed approach utilized a planetary mill for activation of the FAU zeolite before transformation into a high-alumina chabazite structure. Even though the studies of Miyagawa describe a different approach to solid-state zeolite transformation (the procedure is closer to that of the dry-gel method, not a typical solvent-free method), it was included into the scope of the present review, because a lot of useful data were collected during the planetary mill application.

The mentioned reports demonstrated the advantages of the mechanochemical pretreatment automatization as a replacement for manual grinding in the solvent-free route of zeolite production. Furthermore, studies in this field have led to multiple observations, making it possible to systematically summarize knowledge about the possibilities and limitations of this approach. The most important aspects to be discussed below are optimization of the milling parameters (Section 2.1), selection of reagents suitable for milling (Section 2.2), the different effects of manual and automatized procedures (Section 2.3), and the mechanisms of mechanochemical activation(Sections 2.4 and 2.5). In Section 2.6, characteristics of prepared solvent-free zeolites will be compared to the standard materials. Finally, practical recommendations on the choice of characterization methods, both for analysis of the milled mixtures and prepared materials, will be provided in Section 2.7.

\subsection{Optimization of the Milling Parameters}

Unlike the basic manual grinding, the automatized approach opens the possibility to adjust the mechanical energy impact on the reagents by milling parameters optimization. Moreover, when the parameters are set, it ensures the reproducibility of the milling process, whereas manual treatment efficiency and reproducibility depends mainly on human performance. The goal of the parameter adjustments is to provide sufficient mixing and activation while preserving the milling parts from destruction, and the sample from contamination due to wearing off of the milling elements.

\subsubsection{Choice of Milling Parts, Rotation Speed}

The optimization of these parameters is discussed mainly on the basis of the authors' experience with planetary milling, as it is considered the most relevant to potential scale-up among the automatic methods of mechanochemical activation $[9,11,35]$. Similar considerations might be extended, however, to other automatic treatments, e.g., milling by ball mills.

For planetary milling, the market offers a wide variety of sizes and materials for milling bowls and balls. Several practical aspects should be considered during the selection of proper milling parts. The size of the bowl and balls should correspond to the planned volume of reagents. Recommendations from the mill manufacturer should be rigorously followed. The choice of milling parts material depends on the chemical composition of the mixture to be milled. As the starting mixture for zeolite production consists mainly of $\mathrm{Si}$ and $\mathrm{Al}$ sources, the sintered corundum, which is a crystalline form of alumina, seems to be one 
of the appropriate choices because it does not introduce allogenic elements to the synthesis (unlike, for example, zirconia or steel). Such an important parameter as the ball-to-powder mass ratio (BPR) should be adjusted based on the assumption that both higher BPR and at the same time bigger balls (at a constant BPR) lead to increased intensity of milling $[9,35]$. No particular studies concerning the estimation of influence of BPR for zeolite synthesis have been published yet, anyway, for each type of synthesis mixture and milling equipment, finding the right set of parameters is always by trial and error. To estimate if the milling parameters are too intense, chemical analysis of the reagent mixture is recommended after milling to detect potential contamination. In general, the contamination by material coming from the milling parts might be caused by an insufficient amount of the mixture (too large bowl, too high BPR) or too fast rotation speed.

The development of synthetic procedures for the solvent-free preparation of SSZ-13 and mordenite zeolites $[43,46]$ with an application of a Fritsch Pulverisette 6 mill included optimization of the milling speed for the mixtures based on precipitated silica Tixosil 38A (Solvay). It was concluded that the speed of $200 \mathrm{rpm}$ was insufficient, given the amorphous synthesis products. On the basis of chemical analysis of the same mixtures after milling at $600 \mathrm{rpm}$, it was found that the aluminum content was $10 \%$ higher than in the initial mixture, which indicated the corundum milling parts wearing off. A speed of $400 \mathrm{rpm}$ was found to be optimal, with the same $\mathrm{Al}$ content after milling, providing preparation of well crystalline zeolites SSZ-13 and mordenite, without contaminations or by-products. Studies by the other groups (see Table 1) applied parameters from $150 \mathrm{rpm}$ for $1 \mathrm{~h}$ (Miyagawa, planetary milling pretreatment used in FAU to CHA zeolite conversion [47]) to $1200 \mathrm{rpm}$ for $5 \mathrm{~min}$ and $1400 \mathrm{rpm}$ for 25 and $50 \mathrm{~min}$ [44]. Unfortunately, information on how the optimization was performed is not included in these reports. The thorough studies of how exactly speed and time influence milling activation together with the estimation of the energy input might be realized during eventual scale-up parameters adjustments, which is beyond the scope of the present review.

The procedure for the first trial experiment may be suggested on the basis of mill manufacturer recommendations for bowl filling. The amount of reagent mixture should be in a range corresponding to milling bowl size. For example, for the Fritsch Pulverisette 6 planetary mill, the user manual suggests that the capacity of a $250 \mathrm{~mL}$ bowl is $30-125 \mathrm{~mL}$ of the reagent mixture. Ball diameter and number of balls for the specific volume of the bowl should also follow manufacturer recommendations. For the Fritsch Pulverisette 6 planetary mill, the user manual instructs to apply 50 balls of $10 \mathrm{~mm}$ diameter or 45 balls of $15 \mathrm{~mm}$ diameter for a bowl of $250 \mathrm{~mL}$ volume. According to the authors' experience, there was no significant difference in using $10 \mathrm{~mm}$ or $15 \mathrm{~mm}$ balls. Smaller balls were not applied, because the number of $5 \mathrm{~mm}$ balls recommended by the manufacturer was 1500 pieces, and if the mixture turned into a paste during milling, it would have been difficult to separate them. Bigger balls were not applied for considerations connected with too intense milling and the probability of milling parts destruction (also according to the user manual). Optimization of milling speed and time should be performed starting from the lowest speed (e.g., $200 \mathrm{rpm}$ ) and the shortest times (e.g., $5 \mathrm{~min}$ ). After the milling, it should be checked if the mixture activation was effective, which means if high crystallinity zeolite is formed after thermal treatment (synthesis in autoclaves). In cases of the products being amorphous, or the crystallinity being low, a higher speed or longer time should be used in the next trial. On the other hand, if the crystallization was successful, the reduction of time and speed might be considered. Particular examples of milling time optimization strategy will be provided in the following section. After each experiment (especially after applying speed higher than $400 \mathrm{rpm}$ or milling time over $20 \mathrm{~min}$ ) the analysis of chemical contamination of milled mixture is advised. The material from milling parts attrition should not appear in the mixture after milling. 


\subsubsection{Milling Time}

At the optimized speed, the milling time should be kept as short as possible, while maintaining an activation degree sufficient for future crystallization. This strategy aims at minimization of energy consumption. In Figure 2, Powder X-ray Diffraction (pXRD) patterns of synthesis products obtained during the optimization of planetary milling pretreatment time are presented, adapted from Ref. [46]. All the products were obtained after a similar crystallization time $(96 \mathrm{~h})$. At a speed of $400 \mathrm{rpm}, 20-\mathrm{min}$ milling time of the reagents mixture based on precipitated silica was found sufficient to obtain SSZ-13 zeolite with a high degree of crystallinity, whereas the shorter milling times or the manual grinding resulted in amorphous products or incomplete crystallization.

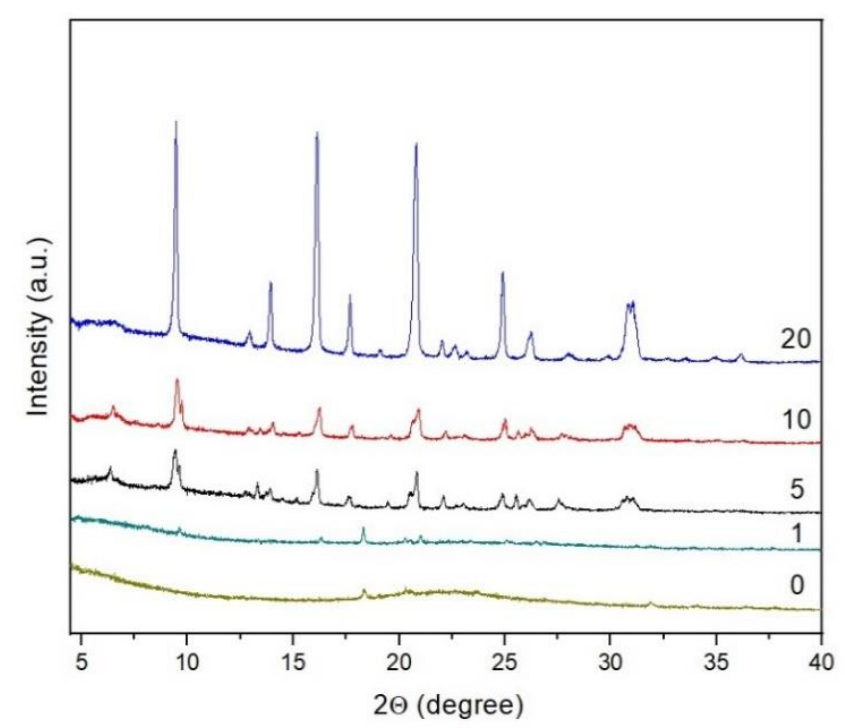

Figure 2. pXRD of as-made SSZ-13 products obtained from mixtures prepared with precipitated silica with an application of milling for various times: 0-only preliminary manual grinding, 1, 5, 10, 20 min of milling. (Reprinted with permission from [46]. Copyright: 2019, John Wiley and sons).

A similar approach to the optimization of grinding time was applied by Gao [42] for the MOR synthesis from a mixture of hydrated sodium silicate as the Si source. Quite short grinding times ranging from 30 to $60 \mathrm{~s}$ were sufficient in that system (Figure 3). Most probably this is connected with the high reactivity of the silica source.

The study by Nada et al. [44] also described optimization of milling time by the gradual increase (Figure 4). They found that the optimized time of ball milling for applied reagents (sodium silicate, silica gel, aluminum sulphate, sodium hydroxide) is $50 \mathrm{~min}$ at $1200 \mathrm{rpm}$, whereas the shorter time ( $25 \mathrm{~min}$ ) resulted in the quartz competing phase.

On the other hand, unnecessary prolongation of the milling pretreatment leads to increased consumption of energy and exploitation of milling parts. It can trigger the side reactions that occur during milling, even before the thermal treatment. To demonstrate this, the mixture used for the preparation of SSZ-13 zeolite in [46] was subjected to $120 \mathrm{~min}$ milling (six times longer than the optimized time), followed by similar thermal treatment as the successful synthesis performed earlier. Although the crystallization of the SSZ13 structure partially occurred, the comparison of ${ }^{27} \mathrm{Al}$ MAS NMR spectra of the milled mixture and the product (unpublished results obtained during work by the Pashkova group, presented in Figure 5) showed the presence of the peak associated with Al octahedral species at $14 \mathrm{ppm}$, formed during the milling process, which did not disappear even after the thermal crystallization. These octahedral species contributed to the lower quality of the SSZ-13 product (in low-defect zeolite phase of high crystallinity, only the framework tetrahedral Al should be present, as seen in the spectrum of SSZ-13 product after $20 \mathrm{~min}$, see Figure $5 b$ ). 


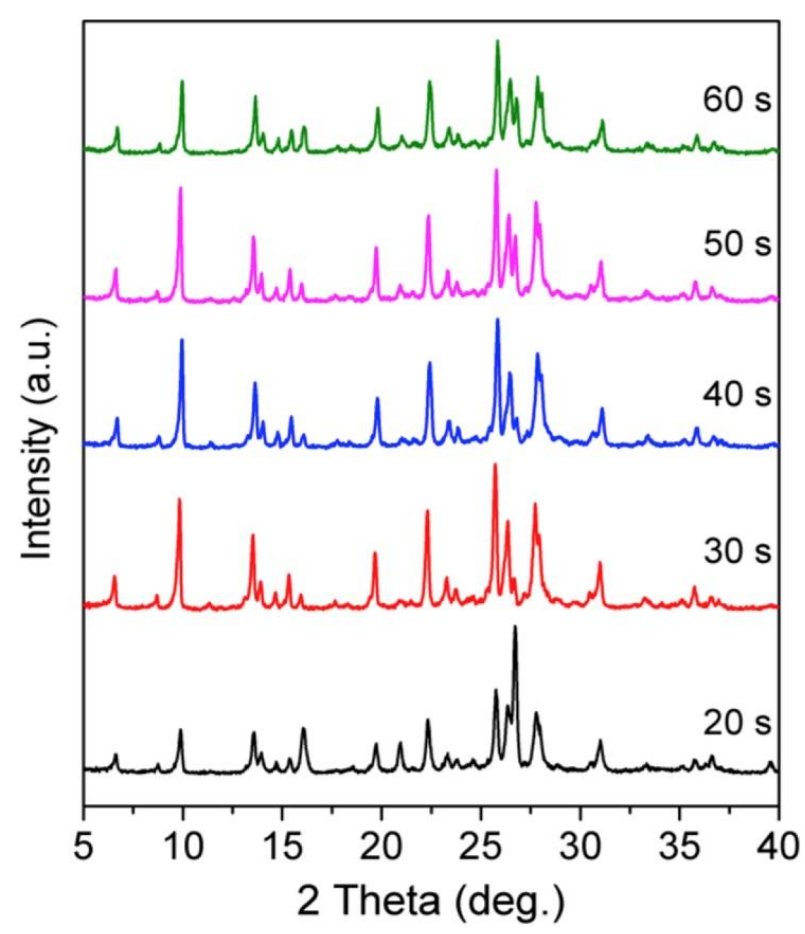

Figure 3. $\mathrm{pXRD}$ of as-synthesized MOR products resulting from mixtures of different grinding pretreatment times. (Reprinted with permission from [42]. Copyright: 2019, Elsevier).

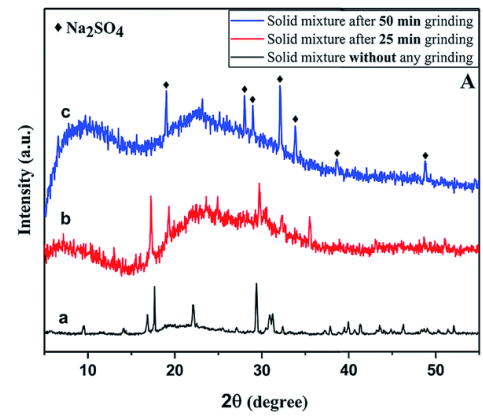

\section{Heating at $180^{\circ} \mathrm{C}$}

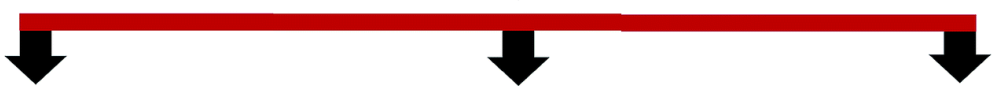

$24 \mathrm{~h}$

$48 \mathrm{~h}$

$72 \mathrm{~h}$
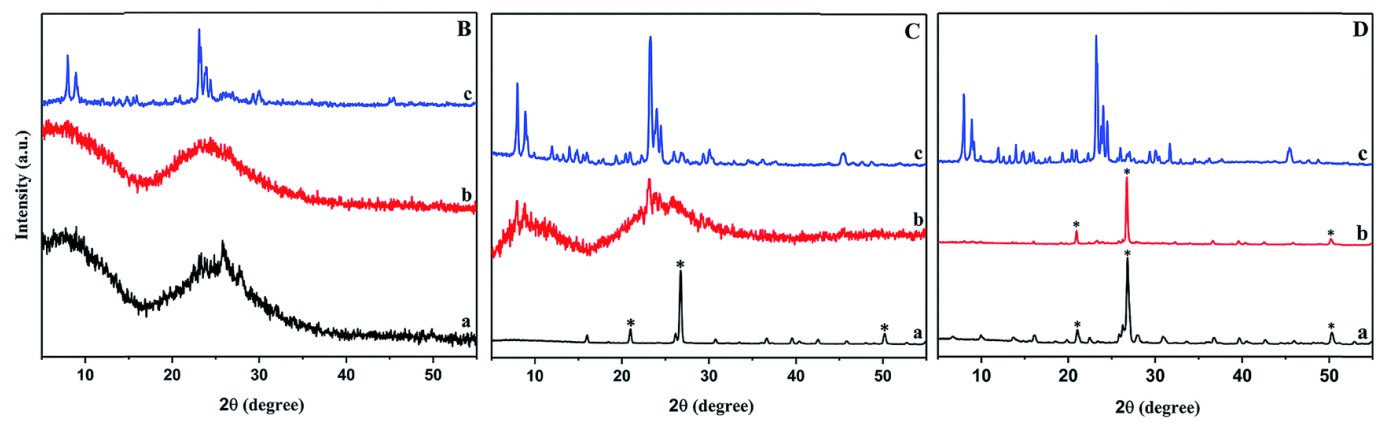

Figure 4. (A) XRD of solid precursor mixture reagent mixture of $\mathrm{Na}_{2} \mathrm{SiO}_{3}, \mathrm{Al}_{2}\left(\mathrm{SO}_{4}\right)_{3}$, and $\mathrm{SiO}_{2}\left(\right.$ equivalent $\mathrm{Na}_{2} \mathrm{O}: \mathrm{Al}_{2} \mathrm{O}_{3}: \mathrm{SiO}_{2}$ ratio of 5:1:30) ground for different periods of time ( $\mathrm{a}-\mathrm{no}$ grinding, $\mathrm{b}-25 \mathrm{~min}$, and $\mathrm{c}-50 \mathrm{~min}$ ). Asterisks in $\mathrm{A}$ indicate $\mathrm{Na}_{2} \mathrm{SO}_{4}$. The XRD of washed products after heating at $180{ }^{\circ} \mathrm{C}$ for periods of: $24 \mathrm{~h}(\mathbf{B}), 48 \mathrm{~h}(\mathbf{C})$, and $72 \mathrm{~h}(\mathbf{D})$. Asterisks in (C) and (D) indicate quartz peaks. (Reprinted from [44]. Published by The Royal Society of Chemistry). 

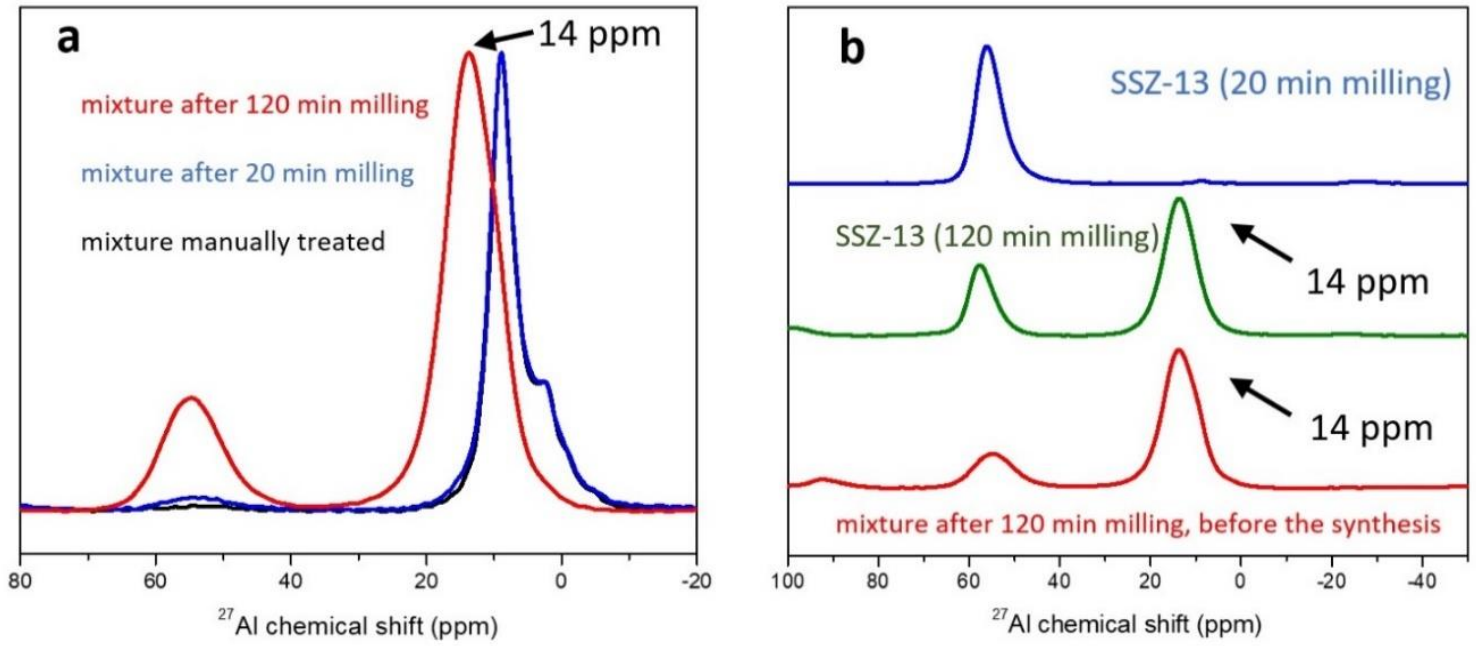

Figure 5. (a) ${ }^{27} \mathrm{Al}$ MAS NMR spectra of the treated mixtures: manually milled for 20 and $120 \mathrm{~min}$; (b) comparison of ${ }^{27} \mathrm{Al}$ MAS NMR spectra of SSZ-13 zeolite products obtained from mixtures milled for 20 and 120 min with the mixture milled for $120 \mathrm{~min}$ before the synthesis.

\subsection{Applicability of the Reagents and Safety Precautions}

\subsubsection{Si and Al Sources, Hydrophilicity, Crystallization Water}

Among the sources of $\mathrm{Si}$ and $\mathrm{Al}$ that are the main components of the synthesis mixture (see Section 1.1.1), only the reagents in a solid state are applicable for dry phase treatments and transformations. That narrows the reagent selection to the range of amorphous silicas (fumed, precipitated) [43,46], solid forms of sodium silicate [44,45], and silica gels. As demonstrated by Miyagawa et al. [47] in the preparation of chabazite by recrystallization of commercial faujasite, zeolites can be used as $\mathrm{Si}$ and $\mathrm{Al}$ sources too, as well as ordered mesoporous silica (SBA-15), which was applied in mordenite synthesis by Gao et al. [42]. Applicable Al sources include different forms of alumina (crystalline and amorphous), Al hydroxide [46], boehmite [42], sodium aluminate [43], and Al salts [44,45]. Si and Al sources used in solvent-free zeolite synthesis with milling pretreatment are listed in Table 1.

Notably, the mentioned $\mathrm{Si}$ and $\mathrm{Al}$ sources often contain bound water, which is released during the treatment, sometimes turning the initially dry mixture into a paste [45]. In some cases, this process is necessary for chemical reactions accompanying the reagent activation $[44,45]$. However, the paste-like mixture is difficult to remove from the mill, because it sticks to the milling parts, and part of the mixture is not possible to remove, which makes the procedure less material-efficient. The mentioned reactions will be discussed further in Sections 2.4 and 2.5 .

When amorphous silica (fumed, precipitated) is the Si source, the hydrophilicity of its surface plays an important role in surface reactions as a ground for further zeolite crystallization, as was recently shown in the work of da Silva et al. [48]. Most probably during the mechanochemical activation, the $\mathrm{OH}$ groups represent reactive sites, which form bonds with $\mathrm{Al}$ during mechanochemical pretreatment. The reactions that occur during milling and the possible activation mechanisms for precipitated silica will be discussed in Section 2.5.

\subsubsection{Organic Structure Directing Agent}

In contrast to $\mathrm{Si}$ and $\mathrm{Al}$ sources, which should be solid in the solvent-free process, the OSDAs could be used in the form of solutions (usually of quaternary ammonium hydroxides), because in a lot of cases the amount of it is low enough to keep the reagent mixture visually dry. Moreover, in some recipes it is possible to minimize the amount of OSDA to $30 \%$ of that required in traditional solvent-based syntheses [46], improving material-efficiency and sustainability. On the other hand, the OSDAs available in solid 
forms (quat salts) are cheaper and easier to handle. Below, the applicability of different forms of OSDAs will be discussed on the basis of data available from published reports and some unpublished data, obtained by the authors.

Due to the fact that intense milling could deliver significantly higher energy to the reagents than manual treatment, the applicability of organic compounds should be evaluated before the milling with consideration for their possible decomposition. For example, when using tetraethylammonium bromide (TEABr) as an OSDA in the mixtures with sodium metasilicate or with precipitated silica at $400 \mathrm{rpm}$ and $20 \mathrm{~min}$ milling time (unpublished results, obtained during work by Pashkova et al. on the production of zeolite Beta), the release of $\mathrm{Br}_{2}$ was observed, indicated by the yellowish-brown color of the mixture and specific smell. Due to this, in further studies, the bromide forms of OSDA were not applied and the hydroxide forms in solution were used instead. On the other hand, Ref. [45] reported successful preparation of ZSM-5 with the application of tetrapropylammonium bromide (TPABr), milled in a synthesis mixture for $5 \mathrm{~min}$ at $1200 \mathrm{rpm}$ in a ball mill without observing $\mathrm{Br}_{2}$ release. The presented data show that the halide forms of OSDAs might be applicable at milder milling conditions or at shorter milling times, whereas if the mixture requires more intense treatment, these forms of OSDA might decompose and should be avoided.

In the case of application of $\mathrm{N}, \mathrm{N}, \mathrm{N}$-trimethyl-1-adamantanammonium hydroxide $(\mathrm{TMAdOH})$, the quaternary ammonium cation stability was estimated upon extended milling (Figure 6, unpublished results obtained during the work in Ref. [46]). A comparison of ${ }^{13} \mathrm{C}$ MAS NMR spectra demonstrated the quaternary ammonium cation stability in the reaction mixture even after extended milling $(120 \mathrm{~min})$, evidenced by unchanged signals, when compared both to the manual grinding and optimized time of $20 \mathrm{~min}$ [see Ref. [46]]. No ammonia smell was detected throughout the milling, also indicating that the quaternary ammonium cation did not decompose.

To sum up, there are no data showing the decomposition of the quaternary ammonium cation upon milling, even at an extended time, so it can be applied without concern. However, if the OSDA is delivered in the form of halide, it potentially might lead to the release of toxic gases at intense milling parameters.

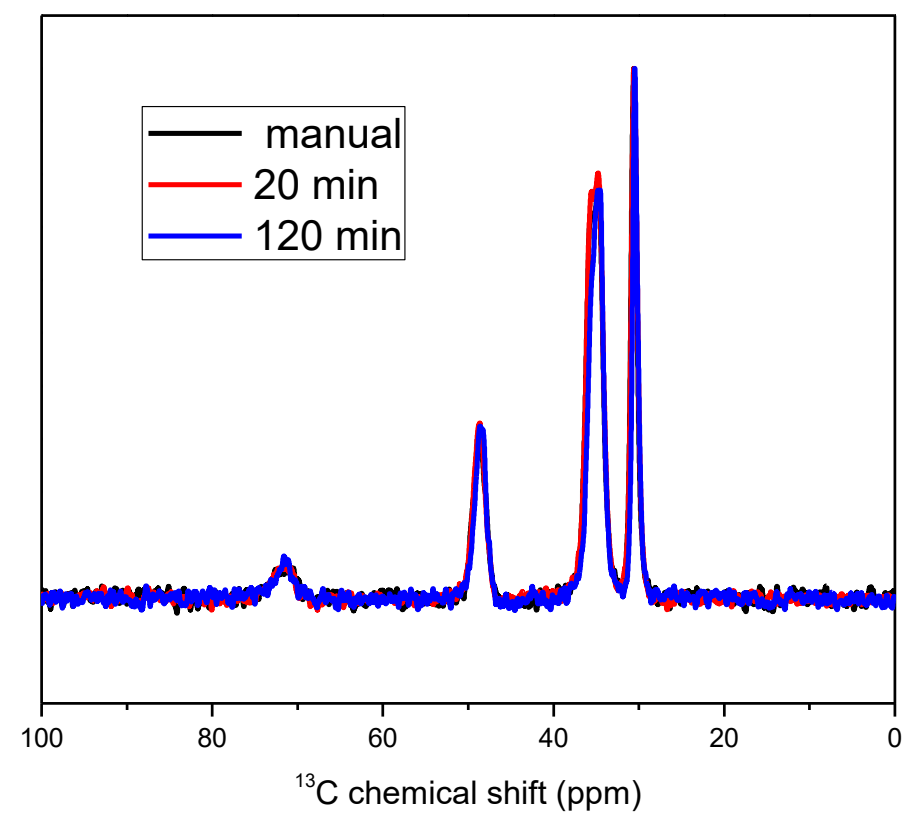

Figure 6. ${ }^{13} \mathrm{C}$ MAS NMR spectra of the reaction mixture applied in Ref. [46]: milled for $120 \mathrm{~min}$, $20 \mathrm{~min}$ and manually ground. 


\subsubsection{Safety Precautions}

In the case discussed above, the toxic gas $\left(\mathrm{Br}_{2}\right)$ was released during the decomposition of quaternary ammonium bromide as a result of the planetary milling. In general, such highenergy treatment might potentially lead to many more undesirable chemical processes, so every possible reaction pathway should be carefully considered before application of reagents. Notably, when it comes to such reagents as ammonium nitrate or aluminum powder, the friction of milling parts might cause enough increase in local temperature to cause detonation. Ref. [44] recommended testing new reaction mixtures at a small scale. Moreover, the potential corrosive effect of reagents (high alkalinity, etc.) on the milling parts should be regarded. Once again, chemical analysis of the post-milling mixture might be recommended to check for contamination coming from the destruction of the milling parts.

\subsection{Manual vs. Automatized Pretreatment Effectivity}

The analyzed reports support the claim of increased effectivity of automatized treatment compared to manual grinding in a mortar.

A comparison of milling with manual activation was reported in Refs [43-46]. In Ref. [45] authors observed that a significantly shorter time ( 5 vs. $15 \mathrm{~min}$ ) was sufficient to ensure the occurrence of the mechanochemical pre-reactions necessary for the formation of crystalline ZSM-5 product. However, for the discussed reagent system, milling did not introduce qualitative chemical changes, it only shortened the time necessary for their development. Further studies by the same group reported the preparation of mordenite and ZSM- 5 structures in an OSDA-free system (which represents a significant advance from the point of view of synthesis sustainability) [44]. The effectivity of pretreatment by the ball mill for 25 and $50 \mathrm{~min}$ and physical mixing (supposedly manual) was compared. Both physical mixing of reagents and the shorter milling pretreatment did not result in stable crystalline zeolites, whereas prolonged (50 min) milling led to zeolite products of high quality (i.e., crystallinity, specific surface area, and catalytic performance in biomass conversion).

In Refs [43,46], planetary milling of mixtures based on precipitated silica (Tixosil 38A, Solvay) and sodium aluminate was compared with manual grinding in a mortar. In all the studied cases, manual pretreatment was not followed by the formation of the crystalline phase during synthesis, while 20 min of milling was found to be efficient for reaction mixture activation and resulted in crystalline zeolites SSZ-13 and mordenite.

To sum up, automatized milling with adjustable parameters could yield the same processes as manual grinding, when mild conditions (shorter time, lower rpm) are applied. The advantageous speed-up of the activation process might be achieved though. On the other hand, more intense treatment should not be considered as simple as manual grinding scale-up or speed-up due to the higher energy delivered to the reagents, which may trigger different chemical transformations, necessary for successful zeolite crystallization from a wider range of (less active) reagents. Reports from different research groups show that, at least in several cases, such reactions are impossible to achieve by manual grinding alone. Examples of these mechanochemical reactions will be discussed in the following section.

\subsection{Elucidation of the Milling Activation Mechanisms}

Effects of milling and grinding such as the reduction of particle size and the increase of active surface of reagent particles, with the consequent reactivity increase, are the most common [9]. Yet, in most reported cases the prerequisite condition to successful zeolite crystallization is the detectable chemical transformation (pre-reactions) occurring already during the milling/grinding step.

For example, in the studies by Nada et al. [45] solid raw materials (sodium silicate $\mathrm{Na}_{2} \mathrm{SiO}_{3} .9 \mathrm{H}_{2} \mathrm{O}$, silica gel $\mathrm{SiO}_{2}$, TPABr as OSDA, $\mathrm{NH}_{4} \mathrm{Cl}$, or $\mathrm{NH}_{4} \mathrm{~F}$, and aluminum hydroxide $\mathrm{Al}(\mathrm{OH})_{3} \mathrm{xH}_{2} \mathrm{O}$ ) were subjected to 5,10 , and $15 \mathrm{~min}$ of manual grinding or $5 \mathrm{~min}$ of ball milling. From the mixtures manually ground for $15 \mathrm{~min}$ and milled for $5 \mathrm{~min}$, ZSM-5 zeolites of high crystallinity were obtained, which additionally had comparable stability upon thermal treatment. The synthesis mixtures after the grinding or milling were analyzed 
by Powder X-ray Diffraction (pXRD), which showed a gradual decrease of the signals associated with starting materials, whereas the new signals, connected with the formation of crystalline $\mathrm{NaCl}$ appeared, indicating the chemical transformation (see Equation (1)). Also, it was observed that the bound water present in the raw materials was released, turning the initially dry mixture into a paste-like phase. The authors described the chemical reactions by the following schemes:

$$
2 \mathrm{NH}_{4} \mathrm{X}+\mathrm{Na}_{2} \mathrm{SiO}_{3} \cdot 9 \mathrm{H}_{2} \mathrm{O} \rightarrow 2 \mathrm{NaX}+\left(\mathrm{NH}_{4}\right)_{2} \mathrm{SiO}_{3}+9 \mathrm{H}_{2} \mathrm{O}
$$

where $\mathrm{X}=\mathrm{Cl}$ or $\mathrm{F}$;

$$
\left(\mathrm{NH}_{4}\right)_{2} \mathrm{SiO}_{3}+9 \mathrm{H}_{2} \mathrm{O} \rightarrow 2 \mathrm{NH}_{4} \mathrm{OH}\left(\mathrm{NH}_{3} \uparrow\right)+\mathrm{H}_{2} \mathrm{SiO}_{3}+7 \mathrm{H}_{2} \mathrm{O}
$$

The following crystallization of ZSM-5 was attributed to the abovementioned prereactions. Notably, the same reactions were achieved by both extended manual treatment (15 $\mathrm{min}$ ) and short (5 $\mathrm{min}$ ) ball milling (see Section 2.3), showing higher effectivity of automatized pretreatment.

Further studies by the same authors were focused on the preparation of ZSM- 5 and MOR zeolites from a mixture of sodium silicate $\mathrm{Na}_{2} \mathrm{SiO}_{3} \cdot 9 \mathrm{H}_{2} \mathrm{O}$, silica gel $\mathrm{SiO}_{2}$, aluminum hydroxide $\mathrm{Al}(\mathrm{OH})_{3} \mathrm{xH}_{2} \mathrm{O}$, and sodium hydroxide $\mathrm{NaOH}$ (Figure 7). In this case, the milling resulted in the loss of all pXRD reflexes of raw materials and led to the formation of sodium sulphate (relevant diffractograms are given in Figure 3, Section 2.1.2) and presumably amorphous aluminosilicate formation.

The reaction equation is given below:

$$
3 \mathrm{Na}_{2} \mathrm{SiO}_{3} \cdot 9 \mathrm{H}_{2} \mathrm{O}+\mathrm{Al}_{2}\left(\mathrm{SO}_{4}\right)_{3} \cdot 18 \mathrm{H}_{2} \mathrm{O} \rightarrow 3 \mathrm{Na}_{2} \mathrm{SO}_{4}+{ }^{\prime \prime} \mathrm{Al}_{2}\left[\mathrm{SiO}_{3}\right]_{3} \text { " }+45 \mathrm{H}_{2} \mathrm{O}
$$

In this case, even when the water was released, the mixture stayed visually dry due to the hydration of sodium sulphate and the adsorption of water on silica gel.

It should be noted that not every successful activation procedure resulted in changes detectable by pXRD. In the report of Miyagawa [47], the performed pXRD analysis did not show any difference before and after the milling. In such a case, to study the activation process other analytic methods might be recommended.

During the studies on solvent-free synthesis of zeolite mordenite, described in [43], the chemical processes that occurred during manual grinding and planetary milling of the synthesis mixture based on precipitated $\mathrm{SiO}_{2}, \mathrm{NaAlO}_{2}$, and $\mathrm{NaOH}$ were investigated using not only pXRD, but also SEM and MAS NMR. The summary of the observed changes is given in Table 2.

Table 2. Summary of changes in the milled mixtures vs. raw reagents. Milled reagent mixtures notation: mixMOR-M-manual pretreatment, mixMOR-N—planetary milling. (Reprinted with permission from [43]. Copyright: 2019, John Wiley and sons).

\begin{tabular}{ccccc}
\hline & pXRD & SEM (Particle Size, $\mu$ m) & ${ }^{27}$ Al MAS NMR & ${ }^{29}$ Si MAS NMR \\
\hline $\mathrm{SiO}_{2}$ & amorph. & $10-100^{\text {a }}$ & not measured & $\mathrm{Q}^{4}(4 \mathrm{Si}), \mathrm{Q}^{3}(3 \mathrm{Si}, 1 \mathrm{OH})$ \\
$\mathrm{NaAlO}_{2}$ & crystalline & not measured & Al tetr. (80 ppm) & not measured \\
mixMOR-M & visible $\mathrm{NaAlO}_{2}$ reflexes & $10-100$ & Al tetr. (80 ppm) & $\mathrm{Q}^{4}(4 \mathrm{Si}), \mathrm{Q}^{3}(3 \mathrm{Si}, 1 \mathrm{OH})$ \\
mixMOR-N & visible $\mathrm{NaAlO}_{2}$ reflexes & $0.5-50$ & Al tetr. (80 ppm) + Al tetr. & $\mathrm{Q}^{4}(4 \mathrm{Si}), \mathrm{Q}^{4}(3 \mathrm{Si}, 1 \mathrm{Al}), \mathrm{Q}^{3}$ \\
& & & networked (58 ppm, broad) & $(3 \mathrm{Si}, 1 \mathrm{OH}), \mathrm{Q}^{2}(2 \mathrm{Si}, 2 \mathrm{OH})$ \\
\hline
\end{tabular}

a $60-150 \mu \mathrm{m}$ according to supplier SDS. 


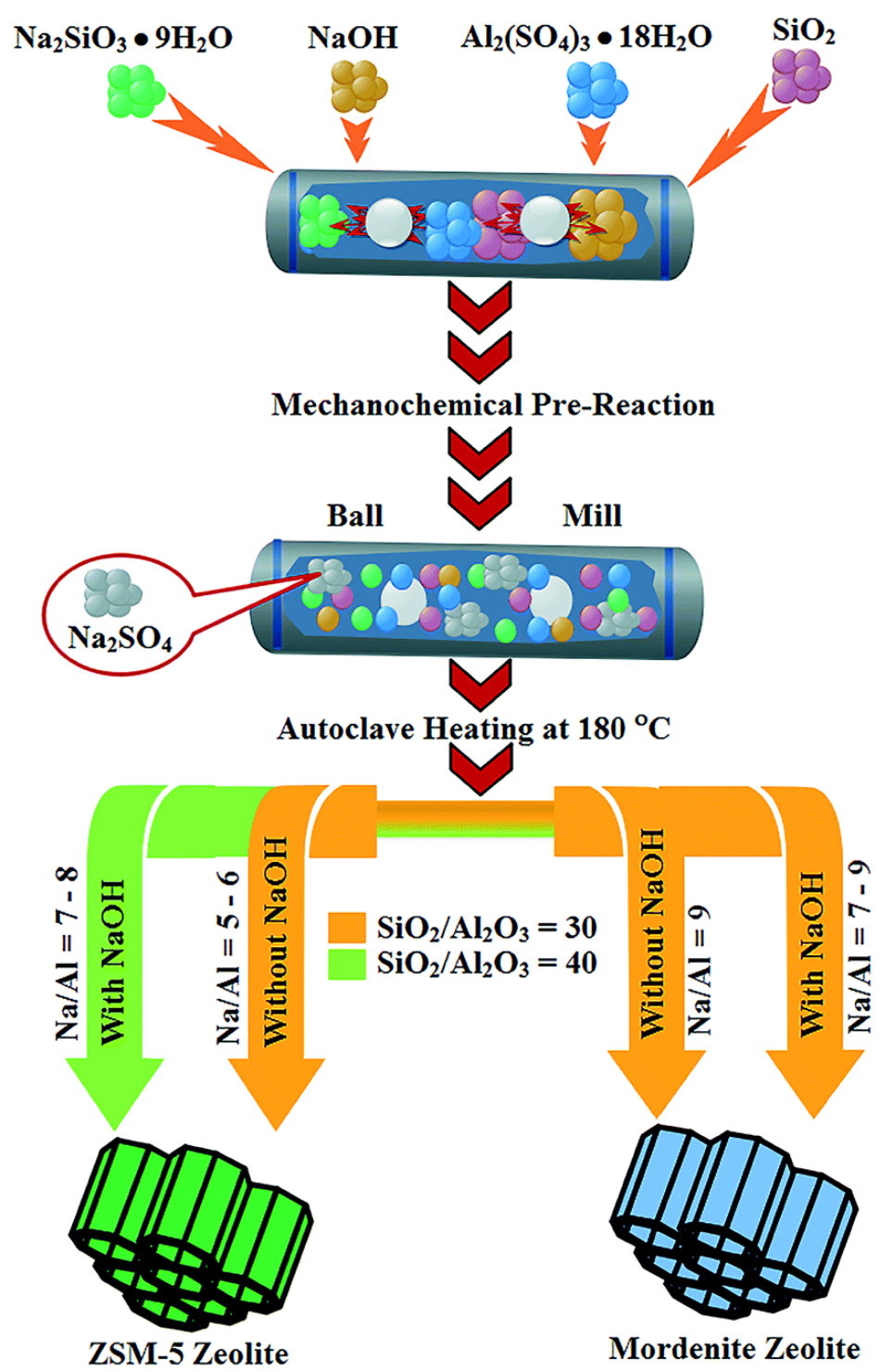

Figure 7. Graphical summary of key reactions steps used and observed phase formation from mechanochemically-assisted solvent-free and template-free zeolite synthesis without using any seeds. (Reprinted from [44]. Published by The Royal Society of Chemistry).

Whereas no detectable changes occurred in the case of manual pretreatment (after which crystallization did not occur), the proposed combination of analytical methods helped to unveil the activation effects of planetary milling, necessary for successful mordenite synthesis. SEM images showed a decrease in particle size, which was not observed in the case of manual grinding. Moreover, the ${ }^{29} \mathrm{Si}$ MAS NMR demonstrated formation of (i) more reactive $\mathrm{Q}^{3}$ and $\mathrm{Q}^{2}$ Si units, which, during the synthesis, can form bonds with $\mathrm{Al}$ atoms to build zeolite structure and (ii) already networked amorphous aluminosilicate, reflected in the presence of $\mathrm{Q}^{4}(1 \mathrm{Al})$ resonance at $-107 \mathrm{ppm}$ in ${ }^{29} \mathrm{Si}$ MAS NMR as well as in ${ }^{27} \mathrm{Al}$ MAS NMR at $58 \mathrm{ppm}$. On the contrary, the manual activation did not result in the formation of the $\mathrm{Si}$ and $\mathrm{Al}$ species mentioned above, therefore, crystallization did not occur.

Figure 8 shows the deconvoluted ${ }^{29} \mathrm{Si}$ MAS NMR spectra of the milled mixture mixMOR-N, demonstrating new signals, which appeared in addition to the $\mathrm{Q}^{\mathrm{X}}$ species present in the parent silica (designated with an asterisk). 


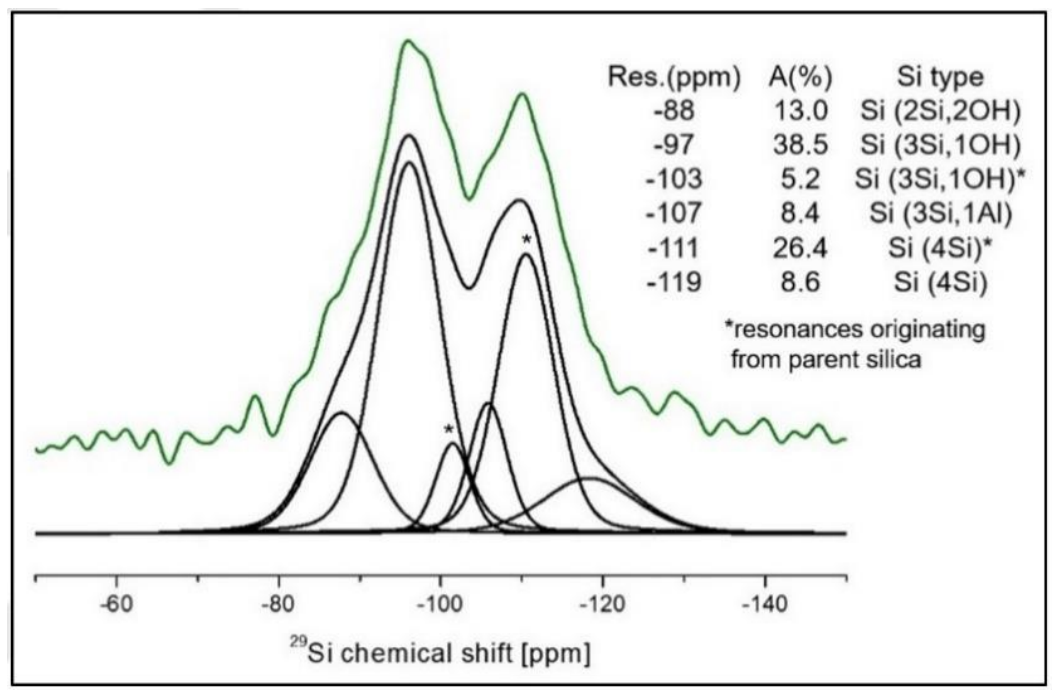

Figure 8. Deconvolution of the ${ }^{29}$ Si MAS NMR spectra of the mixture after milling pretreatment (Reprinted with permission from [43]. Copyright: 2020, John Wiley and sons).

It should be noted that additional experiments were carried out to study the activation effect on the silica source milled alone and followed by manual mixing with the other reagents (unpublished data). The other synthesis parameters were kept the same. This procedure did not result in mordenite crystallization, which led to the conclusion of the importance of milling all the reagents together for effective activation. Only in the case of milling a mixture did the chemical transformations necessary for the further successful crystallization of mordenite occur.

\subsection{Liquid-Assisted vs. Dry Milling Process}

As it was mentioned in the introductory part (Section 1.3), the liquid-assisted milling process may be helpful to reduce friction and prevent excessive attrition of the milling equipment. A small amount of water may be added directly to the milling bowl before milling to a paste-like consistency. When the mixture turns into a paste due to the release of crystallization water [45] or water is applied as a solvent for OSDA [46] and the mixture is not visually dry anymore, the milling process might be considered liquid-assisted too. In most cases, due to the complexity of the reagent mixture (e.g., silica source hydrophilicity [48]) and intricacy of the accompanying processes (i.e., adsorption-release and re-adsorption of water), the quantitative coefficient $\eta$ of the liquid-assisted process (see Section 1.3) is difficult to estimate precisely. A completely dry (so called "neat") or an incipient wetness process (in which the water stays adsorbed and the reaction mixture remains visually dry), may be beneficial from the practical point of view, because it is much easier to handle the dry mixture than a paste, and the reagents are not lost due to sticking to the milling parts. Moreover, in some cases, the presence of water in the milled mixture is not necessary and even unfavorable, because it participates in undesirable chemical reactions.

For example, during the studies of solvent-free zeolite mordenite crystallization from a system consisting of precipitated $\mathrm{SiO}_{2}, \mathrm{NaAlO}_{2}$, and $\mathrm{NaOH}$ [43] the comparison of liquid-assisted milling and the dry (neat) milling process was performed. In the case of milling with water, a significant amount of octahedral $\mathrm{Al}$ species was already detected after milling (by ${ }^{27} \mathrm{Al}$ MAS NMR, see Figure 9a). Even though the studied system led to the crystallization of MOR structure, the mentioned $\mathrm{Al}$ species remained unchanged during the thermal treatment and lowered the quality of the obtained material (Figure 9b, MOR-L). 


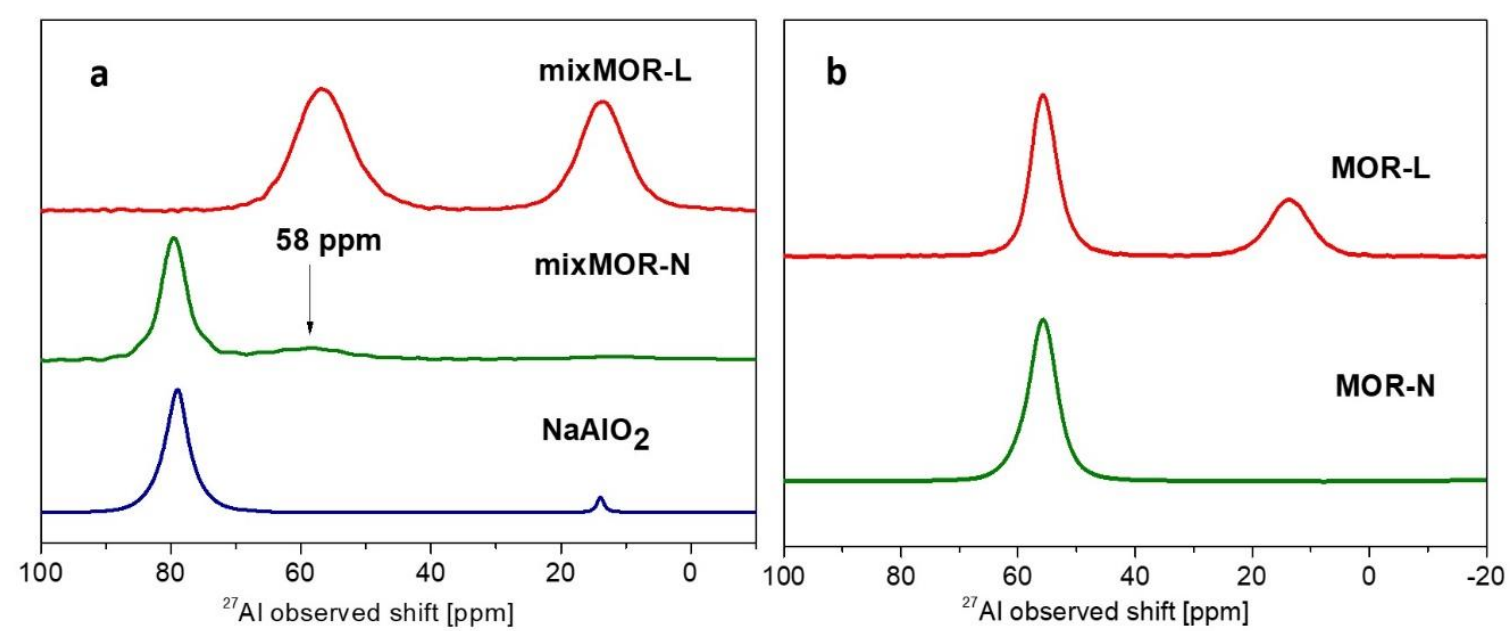

Figure 9. ${ }^{27} \mathrm{Al}$ MAS NMR spectra of (a) mixtures milled with liquid (mixMOR-L) and by neat milling (mixMOR-N) (b) MOR products obtained after crystallization of respective mixtures.

On the other hand, when the reagents were milled in a dry state and water was added directly to the autoclaves before synthesis (keeping the same stoichiometry), the sidereactions leading to the octahedral $\mathrm{Al}$ formation did not occur and high-quality zeolite with all $\mathrm{Al}$ incorporated into the network was obtained (designated as MOR-N).

By contrast, in the syntheses performed by Nada et al. [44,45], discussed in Section 2.4 (Equations (1)-(3)), the water did not directly participate in the mechanochemical prereactions, but was released from the raw reagents and used as a catalyst in the following formation of zeolite network (see also Section 1.1.3).

To summarize, in the liquid-assisted procedure, the mechanochemical reactions in the presence of water should be carefully considered for each particular reagent system because it could lead to undesirable side processes [43] that lower the quality of the product. At the same time, when the water should not participate in the activation pre-reaction, the small ("catalytic") amount of it, which is necessary for the formation of an aluminosilicate network during thermal crystallization, can be added directly to the autoclaves before synthesis, as performed in Ref. [43].

\subsection{Comparison of Characteristics of Prepared Materials}

Almost all reports showed that in the solvent-free process assisted by milling pretreatment it was possible to obtain zeolites with crucial properties desirable for catalytic applications: high crystallinity, low extraframework aluminum content, and comparable micropore sorption capacity as in the case of zeolites prepared by the traditional hydrothermal route.

Authors of proposed novel solvent-free strategies usually carry out a comparison of obtained materials with reference materials synthesized in the laboratory or with commercially available samples. For example, the materials prepared in Ref. [44] were compared with the standard commercial samples (ZSM- 5 and mordenite provided by Zeolyst).

The data in Tables 3 and 4 show that the synthesized "solvent-free" zeolites were close to the reference commercial materials in surface area and crystallinity. Even more important, the obtained samples demonstrated considerable yield and conversion in the biomass conversion process. 
Table 3. Comparison of physical and chemical properties of selected single-phase zeolites. (Reprinted from [44]. Published by The Royal Society of Chemistry).

\begin{tabular}{|c|c|c|c|c|}
\hline Samples ${ }^{a}$ & $\begin{array}{l}\text { Precursor, } \mathrm{Na}_{2} \mathrm{O}: \\
\mathrm{Al}_{2} \mathrm{O}_{3}: \mathrm{SiO}_{2} \mathrm{~b}\end{array}$ & $\begin{array}{l}\text { \% Relative } \\
\text { Crystallinity }\end{array}$ & Surface Area $\left(\mathrm{m}^{2} \mathrm{~g}^{-1}\right)$ & $\begin{array}{l}\text { Product Composition, } \\
\mathrm{Na}_{2} \mathrm{O}: \mathrm{Al}_{2} \mathrm{O}_{3}: \mathrm{SiO}_{2}{ }^{\mathrm{c}}\end{array}$ \\
\hline ZSM-5-5 & $5: 1: 30$ & 95 & 324 & $2.2: 1.0: 26$ \\
\hline ZSM-5-6 & $6: 1: 30$ & 90 & 307 & $1.7: 1.0: 24$ \\
\hline ZSM-5-7 & $7: 1: 40$ (with $\mathrm{NaOH})$ & 94 & 318 & $5.8: 1.0: 33$ \\
\hline ZSM-5-8 & $8: 1: 40$ (with $\mathrm{NaOH})$ & 89 & 298 & $4.9: 1.0: 31$ \\
\hline MOR-7 & $7: 1: 30$ (with $\mathrm{NaOH}$ ) & 92 & 302 & $3.4: 1.0: 13$ \\
\hline MOR-9 & $9: 1: 30$ & 85 & 287 & $4.8: 1.0: 14$ \\
\hline Comm-Na-ZSM-5 & $\mathrm{n} / \mathrm{a}$ & 100 & 361 & $0.93: 1.0: 37$ \\
\hline Comm-Na-MOR & $\mathrm{n} / \mathrm{a}$ & 100 & 371 & $1.55: 1.0: 11$ \\
\hline
\end{tabular}

a Sample names are denoted as: zeolite phase- $\mathrm{Na}_{2} \mathrm{O} / \mathrm{Al}_{2} \mathrm{O}_{3}$ molar ratio in reaction. MOR = mordenite zeolite and "comm" refers to commercial sodium-containing zeolite samples; ${ }^{b}$ Equivalent metal oxide molar ratios in reactions are shown that arise from $\mathrm{Na}_{2} \mathrm{SiO}_{3}$, $\mathrm{Al}_{2}\left(\mathrm{SO}_{4}\right)_{3}$, and $\mathrm{SiO}_{2}$ with and without $\mathrm{NaOH}$ addition. Note that ideally molar equivalents of $\mathrm{Na}$ are sequestered as $\mathrm{Na}_{2} \mathrm{SO}_{4}$, so "free" $\mathrm{Na}$ for reaction is lower (e.g., $5: 1: 30$ would be $2: 1: 30$ for free Na available); ${ }^{\mathrm{c}}$ Relative molar ratios are based on bulk product compositions measured by ICP-OES analysis.

Table 4. Comparison of relative composition and surface area for acid-exchanged single-phase zeolite samples and commercial ZSM-5 and mordenite materials. (Reprinted from [44]. Published by The Royal Society of Chemistry).

\begin{tabular}{|c|c|c|c|c|}
\hline Sample ${ }^{a}$ & $\begin{array}{c}\text { ICP Composition, } \\
\mathrm{Na}_{2} \mathrm{O}: \mathrm{Al}_{2} \mathrm{O}_{3}: \mathrm{SiO}_{2} \mathrm{~b}\end{array}$ & Surface Area $\left(\mathrm{m}^{2} \mathrm{~g}^{-1}\right)$ & $\begin{array}{l}\text { Biomass Conversion (\%) } \\
\text { from Glucose (Cellulose) }\end{array}$ & $\begin{array}{l}\text { HMF Yield (\%) from } \\
\text { Glucose (Cellulose) }\end{array}$ \\
\hline H-ZSM-5-5 & $0.27: 1.0: 33$ & 320 & $83(53)$ & $38(30)$ \\
\hline H-ZSM-5-6 & $0.30: 1.0: 29$ & 311 & $72(49)$ & $42(24)$ \\
\hline Comm H-ZSM-5 & $0.12: 1.0: 41$ & 355 & $82(65)$ & $48(35)$ \\
\hline H-MOR-7 & $0.44: 1.0: 12$ & 296 & $76(43)$ & $31(27)$ \\
\hline H-MOR-9 & $0.72: 1.0: 17$ & 283 & $78(40)$ & $36(22)$ \\
\hline Comm H-MOR & $0.23: 1.0: 13$ & 373 & $88(60)$ & $37(28)$ \\
\hline
\end{tabular}

\footnotetext{
a Sample names are denoted as: zeolite phase- $\mathrm{Na}_{2} \mathrm{O} / \mathrm{Al}_{2} \mathrm{O}_{3}$ molar ratio in reaction. MOR = mordenite zeolite and "comm" refers to
} commercial zeolite samples; ${ }^{b}$ Relative molar ratios are based on bulk product compositions as measured by ICP-OES analysis.

In some cases, it was possible to prepare zeolites with significantly improved characteristics. For example, in the report by Gao et al. [42], the synthesized mordenite product after $48 \mathrm{~h}$ synthesis demonstrated considerably higher micropore volume $\left(0.314 \mathrm{~cm}^{3} / \mathrm{g}\right)$ even at $30 \%$ lower crystallinity compared to the commercial reference zeolite material Nankai MOR (respective micropore volume: $0.093 \mathrm{~cm}^{3} / \mathrm{g}$ ).

Zeolites prepared in Refs [43,46] were compared not with the commercial zeolites, but with the reference materials prepared in the laboratory according to the literature recipes [49,50]. Key parameters such as the amount of extraframework Al and the micropore volume were considered (Table 5). The comparison demonstrated that the successful examples of solvent-free synthesis MOR-N and SSZ-13-P96 showed a negligible amount of extraframework $\mathrm{Al}$, the same as in the reference samples prepared by classical hydrothermal synthesis. Solvent-free synthesis of mordenite yielded the same micropore volume as the reference sample, whereas the solvent-free SSZ-13 sample had lower micropore volume.

Table 5. Characteristics of selected examples of solvent-free zeolites prepared with milling pretreatment vs. reference zeolites prepared by classical hydrothermal method.

\begin{tabular}{|c|c|c|c|c|c|}
\hline Sample & Sources & Synthesis Time (h) & $\mathrm{Si} / \mathrm{Al}^{\mathrm{a}}$ & EfAl (\%) ${ }^{b}$ & $V_{m i}\left(\mathrm{~cm}^{3} / g\right)^{c}$ \\
\hline SSZ-13-P96, Milling & precipitated silica, aluminum hydroxide & 96 & 7.2 & $<1$ & 0.16 \\
\hline SSZ-13, Reference & zeolite $\mathrm{Y}$, sodium silicate & 96 & 7.2 & $<1$ & 0.21 \\
\hline MOR-N, Milling & precipitated silica, sodium aluminate & 24 & 6.2 & $<1$ & 0.19 \\
\hline MOR, Reference & precipitated silica, sodium aluminate & 24 & 5.4 & $<1$ & 0.19 \\
\hline
\end{tabular}

${ }^{a}$ based on XRF; ${ }^{b}$ extraframework $\mathrm{Al}$, calculated on basis of ${ }^{27} \mathrm{Al}$ MAS NMR; ${ }^{\mathrm{c}}$ micropore volume, calculated on basis of t-plot. 
On the contrary, the crystal size and shape of materials prepared by a solvent-free strategy in general, and, in particular, with milling pretreatment, demonstrate differences compared with the reference zeolite materials. As it was reported in Refs [51,52], and references therein, the $\mathrm{H}_{2} \mathrm{O} / \mathrm{SiO}_{2}$ ratio (and contribution of additives, e.g., $\mathrm{NaOH}$ ) could be considered the key parameters to control the size and morphology of prepared MFI zeolites.

These considerations might be applicable for the solvent-free processes with milling pretreatment, because the solvent-free crystallization mechanisms during thermal treatment with a limited amount of water are expected to be similar, independent of how the mixture activation was performed before the synthesis.

Yet, on the basis of the authors' experience with zeolite synthesis and unpublished data obtained during studies described in Refs [43,46], the crystal size and shape in the solvent-free processes cannot be exactly "predicted" before the synthesis. They are a result of the interplay of multiple crystallization parameters (alkalinity, $\mathrm{H}_{2} \mathrm{O} / \mathrm{SiO}_{2}$, synthesis temperature, character of applied reagents, even autoclaves and oven characteristics, etc.).

For example, in studies by Kornas et al. [43] the mordenite prepared by the solventfree route was compared with reference material prepared from the same reagents and with the same synthesis time and temperature, but in solution (Figure 10). The solvent-free zeolite (MOR-N) showed bigger crystals with sharp edges compared to smaller crystals of different morphologies obtained by the traditional route (MOR-R).

The effects of solvent-free crystallization processes described in other studies cannot be fairly compared, because the reference samples were either synthesized in the laboratory using different reagents, like in [46], or are commercial products.

It is worth noting that when the Steam Assisted Conversion was applied for synthesis performed by Miyagawa et al. [47], the differences in crystal size and morphology were not observed (Figure 11). It shows that the crystallization by steam-assisted process is probably closer to the traditional solvent route than the solvent-free synthesis.

To conclude this Section, although the solvent-free processes might lead to materials with key characteristics that are comparable to traditional zeolites, and could be successfully used as a basis for catalytic systems [44], additional important insights need to be obtained in this area, for example on the mechanisms of crystallization with a limited amount of water and better control over size and morphology.

\subsection{Characterization "Toolbox"}

Characterization of the milled mixtures is important both for understanding the fundamental processes (chemical transformations) behind the reagent activation and detecting undesirable reactions, which helps to adjust the milling parameters and reagent composition.

Furthermore, as demonstrated in the previous section, a comparison of the characteristics of zeolite products prepared by "simplified" synthesis methods with the traditionally prepared materials currently applied in industry is regarded as a pivotal point in the development of alternative synthesis pathways. To prove that the quality of prepared materials is not lower compared to standard zeolites, it is necessary to perform comparative studies with regard to the potential applicability of prepared materials as catalysts. On the basis of the reports discussed above, the applicability of analytical methods in investigations of milled mixtures and obtained products is summarized in Table 6. 


\section{MOR-N}
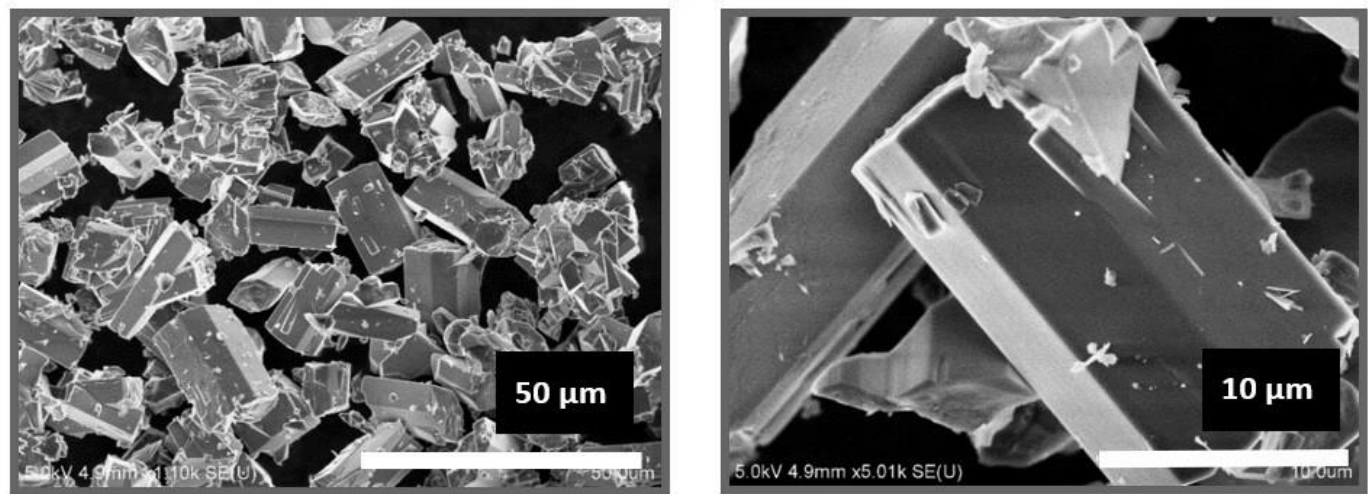

\section{MOR-R}
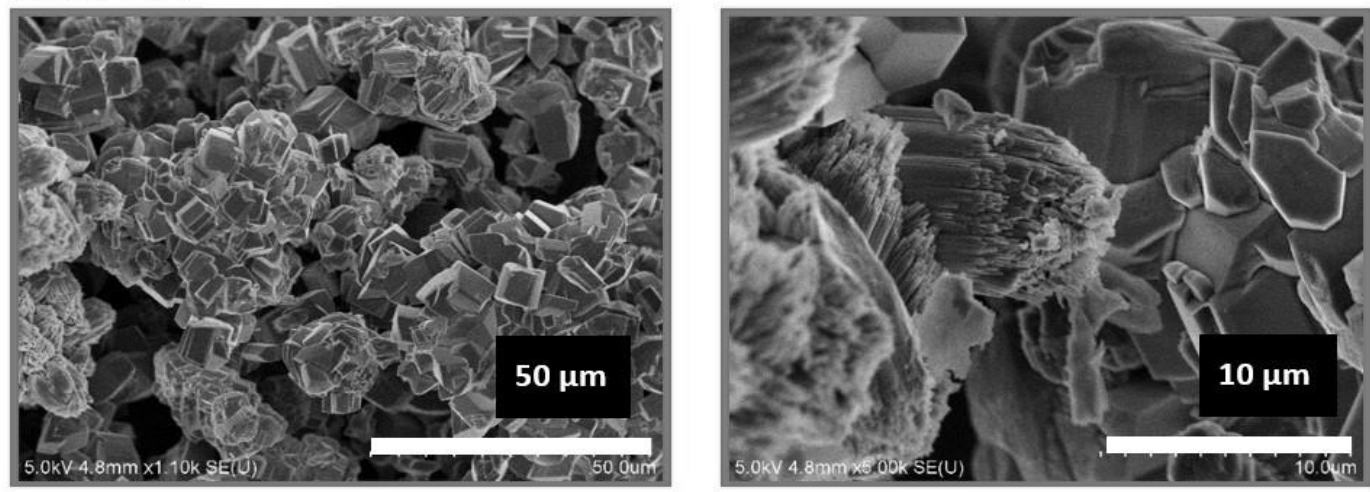

Figure 10. Comparison of the zeolites prepared by traditional synthesis with their solvent-free counterparts showing differences in crystal size and morphology (Reprinted with permission from [43]. Copyright: 2019, John Wiley and sons).
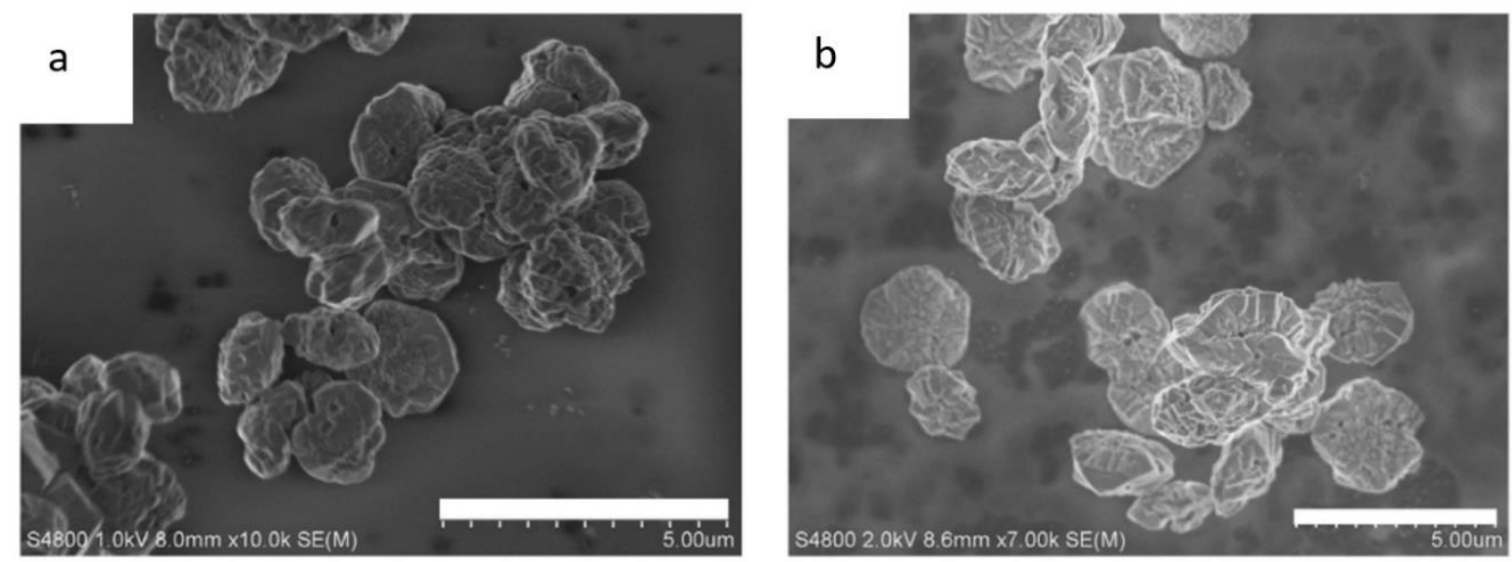

Figure 11. (a) CHA obtained by mechanochemical-assisted steam treatment (18 h) at FAU/KOH of 15; (b) CHA obtained by conventional hydrothermal synthesis. (Reprinted with permission from [47], Copyright: 2019, Elsevier). 
Table 6. Applicability of analytical methods for characterization of milled mixtures and obtained products.

\begin{tabular}{|c|c|c|}
\hline Characterization Method & Analysis of Milled Mixture & Analysis of Zeolite Products \\
\hline Powder X-ray Diffraction & $\begin{array}{l}\text { (i) amorphization of crystalline } \\
\text { raw materials } \\
\text { (ii) formation of new crystalline phases as a } \\
\text { result of mechanochemical pre-reactions }\end{array}$ & $\begin{array}{l}\text { (i) detection of zeolite product } \\
\text { (ii) estimation of product crystallinity } \\
\text { and purity } \\
\text { (iii) significant presence of (unreacted) } \\
\text { amorphous phase }\end{array}$ \\
\hline $\begin{array}{l}\text { Chemical analysis } \\
\text { (e.g., X-ray Fluorescence) }\end{array}$ & detection of milling parts attrition & $\begin{array}{l}\text { estimation of } \mathrm{Si} / \mathrm{Al} \text { ratio or residual cation } \\
\text { composition }\left(\text { e.g., } \mathrm{Na}^{+}\right) \text {. }\end{array}$ \\
\hline Scanning Electron Microscopy & $\begin{array}{l}\text { changes in the reagent particle size } \\
\text { (fragmentation or aggregation of particles and } \\
\text { crystals) }\end{array}$ & $\begin{array}{l}\text { crystal size and morphology } \\
\text { purity, i.e., amorphous phase, unreacted } \\
\text { sources, by-products with different } \\
\text { crystal morphology }\end{array}$ \\
\hline $\begin{array}{l}\text { Magic Angle Spinning } \\
\text { Nuclear Magnetic Resonance }\end{array}$ & $\begin{array}{l}\text { (i) elucidation of changes in } \mathrm{Si} \text { and } \mathrm{Al} \text { state } \\
\text { and their pre-networking }\left({ }^{27} \mathrm{Al} \text { and }{ }^{29} \mathrm{Si}\right. \\
\text { MAS NMR) } \\
\text { (ii) evaluation of the applicability of } \\
\text { reagents (undesirable decomposition) }\end{array}$ & $\begin{array}{l}\text { Si and } \mathrm{Al} \text { state (amount of } \\
\text { extra-framework } \mathrm{Al}) \\
\text { framework } \mathrm{Si} / \mathrm{Al} \text { ratio }\end{array}$ \\
\hline $\begin{array}{l}\text { Sorption studies } \\
\text { (e.g., nitrogen adsorption) }\end{array}$ & not applicable & $\begin{array}{ll}\text { (i) } & \text { micropores' accessibility } \\
\text { (ii) eventual mesopores formation } \\
\text { (iii) external surface area (corresponding to } \\
& \text { amount of surface defects) }\end{array}$ \\
\hline $\begin{array}{l}\text { Fourier Transform Infra-Red (FT IR) } \\
\text { spectroscopic analysis of adsorbed probe } \\
\text { molecules, temperature-programmed } \\
\text { desorption (TPD) of } \mathrm{NH}_{3}\end{array}$ & possible, but no published reports available & $\begin{array}{l}\text { strength and distribution of the acidic sites } \\
\text { (Brønsted and Lewis [53]) }\end{array}$ \\
\hline catalytic tests & not applicable & catalytic activity and selectivity \\
\hline
\end{tabular}

\section{Conclusions}

In addition to the multiple advantages of the solvent-free approach to zeolite synthesis [12], the application of automatized milling instead of manual grinding is especially beneficial in:

(1) reproducibility of parameters, elimination of human factors and necessity of manual work;

(2) better relevance to industrial scale-up;

(3) high energy activation: the same chemical reactions might be achieved in a shorter time than in the case of manual treatment [45]; zeolite crystallization occurs in the systems where manual grinding was not effective at all $[43,44,46]$.

On the other hand, the limitations of this method should be kept in mind:

(1) it is not possible to eliminate water from the synthesis mixture totally (applies to all solvent-free crystallization of zeolites, except the fluoride route) [12];

(2) reagent applicability is limited ( $\mathrm{Si}$ and $\mathrm{Al}$ sources should be applied only in the solid state; such aspects as decomposition, safety, water release, and side-reactions should be regarded);

(3) parameters optimization should be performed carefully because too intense parameters could lead to the destruction of the milling parts.

Solvent-free synthesis and, in particular, the mechanochemical automatized approach is an exciting new area in the field of zeolite synthesis, with a capacity to spawn the development of new experimental studies, providing a broader knowledge base and trialand-error reports, opening the possibilities of solvent-free route implementation in the industrial production of zeolites for a sustainable future. 
Author Contributions: Conceptualization, V.P.; methodology, software, J.E.O. and P.K.; formal analysis, A.K., J.E.O., P.K. and V.P.; investigation, A.K., J.E.O., P.K. and V.P.; data curation, A.K., J.E.O. and P.K.; writing—original draft preparation, V.P.; writing—review and editing, J.E.O., A.K. and V.P.; visualization, A.K., J.E.O. and V.P.; supervision, project administration, V.P.; funding acquisition, V.P. All authors have read and agreed to the published version of the manuscript.

Funding: This research was funded by GRANT AGENCY OF THE CZECH REPUBLIC (Grantová Agentura České Republiky) under grant number 17-09188Y.

Institutional Review Board Statement: Not applicable.

Informed Consent Statement: Not applicable.

Acknowledgments: The authors acknowledge the contribution of Adam Benda and Vaclav Srb to the experimental work; valuable suggestions of Jiri Dedecek during writing; Haunani Thomas for English proofreading; Czech Academy of Sciences under Strategy AV21; project Pro-NanoEnviCz (CZ.02.1.01/0.0/0.0/16_013/0001821); project CATAMARAN, Reg. No. CZ.02.1.01/0.0/0.0/16_013/ 0001801, integrated into the National Sustainability Programme I of the Ministry of Education, Youth and Sports of the Czech Republic (MEYS) through the project Development of the UniCRE Centre (LO1606); Solvay SILICA for free samples of Tixosil ${ }^{\mathrm{TM}}$ materials used for experiments.

Conflicts of Interest: The authors declare no conflict of interest. The funders had no role in the design of the study; in the collection, analyses, or interpretation of data; in the writing of the manuscript, or in the decision to publish the results.

\section{References}

1. Vermeiren, W.; Gilson, J.P. Impact of Zeolites on the Petroleum and Petrochemical Industry. Top. Catal. 2009, 52, 1131-1161. [CrossRef]

2. Guisnet, M.; Bourdillon, G.; Gueguen, C. Coke Poisoning Effect on Xylene Isomerization and on N-Hexane Cracking over H-Offretite. Zeolites 1984, 4, 308-309. [CrossRef]

3. Weitkamp, J. Zeolites and catalysis. Solid State Ion. 2000, 131, 175-188. [CrossRef]

4. Martinez, C.; Corma, A. Inorganic molecular sieves: Preparation, modification and industrial application in catalytic processes. Coord. Chem. Rev. 2011, 255, 1558-1580. [CrossRef]

5. $\quad$ Bedard, R.L.; Wilson, S.T.; Vail, L.D.; Bennett, J.M.; Flanigen, E.M. The Next Generation—Synthesis, Characterization, and Structure of Metal Sulfide-Based Microporous Solids. Stud. Surf. Sci. Catal. 1989, 49, 375-387.

6. Cundy, C.S.; Cox, P.A. The hydrothermal synthesis of zeolites: Precursors, intermediates and reaction mechanism. Microporous Mesoporous Mater. 2005, 82, 1-78. [CrossRef]

7. Meng, X.J.; Xiao, F.S. Green Routes for Synthesis of Zeolites. Chem. Rev. 2014, 114, 1521-1543. [CrossRef]

8. Wang, Y.Q.; Xiao, F.S. Understanding Mechanism and Designing Strategies for Sustainable Synthesis of Zeolites: A Personal Story. Chem. Rec. 2016, 16, 1054-1066. [CrossRef]

9. Do, J.L.; Friscic, T. Chemistry 2.0: Developing a New, Solvent-Free System of Chemical Synthesis Based on Mechanochemistry. Synlett 2017, 28, 2066-2092. [CrossRef]

10. James, S.L.; Adams, C.J.; Bolm, C.; Braga, D.; Collier, P.; Friscic, T.; Grepioni, F.; Harris, K.D.M.; Hyett, G.; Jones, W.; et al. Mechanochemistry: Opportunities for new and cleaner synthesis. Chem. Soc. Rev. 2012, 41, 413-447. [CrossRef]

11. Do, J.L.; Friscic, T. Mechanochemistry: A Force of Synthesis. ACS Cent. Sci. 2017, 3, 13-19. [CrossRef]

12. Wu, Q.M.; Meng, X.J.; Gao, X.H.; Xiao, F.S. Solvent-Free Synthesis of Zeolites: Mechanism and Utility. Acc. Chem. Res. 2018, 51, 1396-1403. [CrossRef]

13. Nagy, J.B.; Aiello, R.; Giordano, G.; Katovic, A.; Testa, F.; Kónya, Z.; Kiricsi, I. Isomorphous Substitution in Zeolites. In Characterization II; Springer: Berlin/Heidelberg, Germany, 2006; Volume 5, pp. 365-478.

14. Pal-Borbely, G.; Szegedi, A.; Beyer, H.K. Solid-state recrystallization of aluminum-containing kanemite varieties to ferrierite. Microporous Mesoporous Mater. 2000, 35-36, 573-584. [CrossRef]

15. Mintova, S.; Valtchev, V. Effect of the silica source on the formation of nanosized silicalite-1: An in situ dynamic light scattering study. Microporous Mesoporous Mater. 2002, 55, 171-179. [CrossRef]

16. Zones, S.I.; Darton, R.J.; Morris, R.; Hwang, S.J. Studies on the role of fluoride ion vs reaction concentration in zeolite synthesis. J. Phys. Chem. B 2005, 109, 652-661. [CrossRef] [PubMed]

17. Zones, S.I.; Hwang, S.J.; Elomari, S.; Ogino, I.; Davis, M.E.; Burton, A.W. The fluoride-based route to all-silica molecular sieves; a strategy for synthesis of new materials based upon close-packing of guest-host products. C. R. Chim. 2005, 8, 267-282. [CrossRef]

18. Ren, L.M.; Wu, Q.M.; Yang, C.G.; Zhu, L.F.; Li, C.J.; Zhang, P.L.; Zhang, H.Y.; Meng, X.J.; Xiao, F.S. Solvent-Free Synthesis of Zeolites from Solid Raw Materials. J. Am. Chem. Soc. 2012, 134, 15173-15176. [CrossRef]

19. Xu, W.Y.; Dong, J.X.; Li, J.P.; Li, J.Q.; Wu, F. A Novel Method for the Preparation of Zeolite Zsm-5. J. Chem. Soc. Chem. Commun. 1990, 755-756. [CrossRef] 
20. Rao, P.R.H.P.; Matsukata, M. Dry-gel conversion technique for synthesis of zeolite BEA. Chem. Commun. 1996, 1441-1442. [CrossRef]

21. Matsukata, M.; Nishiyama, N.; Ueyama, K. Zeolitic Membrane Synthesized on a Porous Alumina Support. J. Chem. Soc. Chem. Commun. 1994, 339-340. [CrossRef]

22. Matsukata, M.; Nishiyama, N.; Ueyama, K. Preparation of a Thin Zeolitic Membrane. Stud. Surf. Sci. Catal. 1994, 84, 1183-1190.

23. Pan, T.; Wu, Z.J.; Yip, A.C.K. Advances in the Green Synthesis of Microporous and Hierarchical Zeolites: A Short Review. Catalysts 2019, 9, 274. [CrossRef]

24. Naik, S.P.; Chiang, A.S.T.; Thompson, R.W. Synthesis of zeolitic mesoporous materials by dry gel conversion under controlled humidity. J. Phys. Chem. B 2003, 107, 7006-7014. [CrossRef]

25. Han, S.W.; Kim, J.; Ryoo, R. Dry-gel synthesis of mesoporous MFI zeolite nanosponges using a structure-directing surfactant. Microporous Mesoporous Mater. 2017, 240, 123-129. [CrossRef]

26. Zhang, J.G.; Li, X.P.; Liu, J.P.; Wang, C.B. A Comparative Study of MFI Zeolite Derived from Different Silica Sources: Synthesis, Characterization and Catalytic Performance. Catalysts 2019, 9, 13. [CrossRef]

27. Jin, Y.Y.; Sun, Q.; Qi, G.D.; Yang, C.G.; Xu, J.; Chen, F.; Meng, X.J.; Deng, F.; Xiao, F.S. Solvent-Free Synthesis of Silicoaluminophosphate Zeolites. Angew. Chem. Int. Ed. 2013, 52, 9172-9175. [CrossRef]

28. Wang, X.; Wu, Q.M.; Chen, C.Y.; Pan, S.X.; Zhang, W.P.; Meng, X.J.; Maurer, S.; Feyen, M.; Muller, U.; Xiao, F.S. Atom-economical synthesis of a high silica CHA zeolite using a solvent-free route. Chem. Commun. 2015, 51, 16920-16923. [CrossRef]

29. Wu, Q.M.; Liu, X.L.; Zhu, L.F.; Ding, L.H.; Gao, P.; Wang, X.; Pan, S.X.; Bian, C.Q.; Meng, X.J.; Xu, J.; et al. Solvent-Free Synthesis of Zeolites from Anhydrous Starting Raw Solids. J. Am. Chem. Soc. 2015, 137, 1052-1055. [CrossRef]

30. Wu, Q.M.; Wang, X.; Qi, G.D.; Guo, Q.; Pan, S.X.; Meng, X.J.; Xu, J.; Deng, F.; Fan, F.T.; Feng, Z.C.; et al. Sustainable Synthesis of Zeolites without Addition of Both Organotemplates and Solvents. J. Am. Chem. Soc. 2014, 136, 4019-4025. [CrossRef] [PubMed]

31. Xiong, X.; Yuan, D.Z.; Wu, Q.M.; Chen, F.; Meng, X.J.; Lv, R.H.; Dai, D.; Maurer, S.; McGuire, R.; Feyen, M.; et al. Efficient and rapid transformation of high silica CHA zeolite from FAU zeolite in the absence of water. J. Mater. Chem. A 2017, 5, 9076-9080. [CrossRef]

32. Petkowicz, D.I.; Mignoni, M.L.; dos Santos, J.H.Z. Dry-gel process for zeolite synthesis: Some fundamental aspects. Microporous Mesoporous Mater. 2019, 279, 92-98. [CrossRef]

33. Liu, Z.Y.; Wu, D.; Ren, S.; Chen, X.Q.; Qiu, M.H.; Liu, G.J.; Zeng, G.F.; Sun, Y.H. Facile one-pot solvent-free synthesis of hierarchical ZSM-5 for methanol to gasoline conversion. RSC. Adv. 2016, 6, 15816-15820. [CrossRef]

34. Zhu, L.F.; Zhang, J.; Wang, L.; Wu, Q.M.; Bian, C.Q.; Pan, S.X.; Meng, X.J.; Xiao, F.S. Solvent-free synthesis of titanosilicate zeolites. J. Mater. Chem. A 2015, 3, 14093-14095. [CrossRef]

35. Burmeister, C.F.; Kwade, A. Process engineering with planetary ball mills. Chem. Soc. Rev. 2013, 42, 7660-7667. [CrossRef] [PubMed]

36. Wakihara, T.; Ichikawa, R.; Tatami, J.; Endo, A.; Yoshida, K.; Sasaki, Y.; Komeya, K.; Meguro, T. Bead-Milling and Postmilling Recrystallization: An Organic Template-free Methodology for the Production of Nano-zeolites. Cryst. Growth Des. 2011, 11, 955-958. [CrossRef]

37. Zhai, M.; Li, L.Y.; Ba, Y.L.; Zhu, K.K.; Zhou, X.G. Fabricating ZSM-23 with reduced aspect ratio through ball-milling and recrystallization: Synthesis, structure and catalytic performance in N-heptane hydroisomerization. Catal. Today 2019, 329, 82-93. [CrossRef]

38. Liu, Z.D.; Zhu, J.; Wakihara, T.; Okubo, T. Ultrafast synthesis of zeolites: Breakthrough, progress and perspective. Inorg. Chem. Front. 2019, 6, 14-31. [CrossRef]

39. Joshi, H.; Ochoa-Hernandez, C.; Nurenberg, E.; Kang, L.Q.; Wang, F.R.; Weidenthaler, C.; Schmidt, W.; Schuth, F. Insights into the mechanochemical synthesis of Sn-beta: Solid-state metal incorporation in beta zeolite. Microporous Mesoporous Mater. $2020,309$. [CrossRef]

40. Kanie, K.; Sakaguchi, M.; Muto, F.; Horie, M.; Nakaya, M.; Yokoi, T.; Muramatsu, A. Mechanochemically assisted hydrothermal synthesis of Sn-substituted MFI-type silicates. Sci. Technol. Adv. Mater. 2018, 19, 545-553. [CrossRef] [PubMed]

41. Hammond, C.; Conrad, S.; Hermans, I. Simple and Scalable Preparation of Highly Active Lewis Acidic Sn-beta. Angew. Chem. Int. Ed. 2012, 51, 11736-11739. [CrossRef] [PubMed]

42. Gao, W.Z.; Amoo, C.C.; Zhang, G.H.; Javed, M.; Mazonde, B.; Lu, C.X.; Yang, R.Q.; Xing, C.; Tsubaki, N. Insight into solvent-free synthesis of MOR zeolite and its laboratory scale production. Microporous Mesoporous Mater. 2019, 280, 187-194. [CrossRef]

43. Kornas, A.; Olszowka, J.E.; Urbanova, M.; Mlekodaj, K.; Brabec, L.; Rathousky, J.; Dedecek, J.; Pashkova, V. Milling Activation for the Solvent-Free Synthesis of the Zeolite Mordenite. Eur. J. Inorg. Chem. 2020, 2020, 2791-2797. [CrossRef]

44. Nada, M.H.; Larsen, S.C.; Gillan, E.G. Mechanochemically-assisted solvent-free and template-free synthesis of zeolites ZSM-5 and mordenite. Nanoscale Adv. 2019, 1, 3918-3928. [CrossRef]

45. Nada, M.H.; Gillan, E.G.; Larsen, S.C. Mechanochemical reaction pathways in solvent-free synthesis of ZSM-5. Microporous Mesoporous Mater. 2019, 276, 23-28. [CrossRef]

46. Pashkova, V.; Mlekodaj, K.; Klein, P.; Brabec, L.; Zouzelka, R.; Rathousky, J.; Tokarova, V.; Dedecek, J. Mechanochemical Pretreatment for Efficient Solvent-Free Synthesis of SSZ-13 Zeolite. Chem.-Eur. J. 2019, 25, 12068-12073. [CrossRef]

47. Miyagawa, S.; Miyake, K.; Hirota, Y.; Nishiyama, N.; Miyamoto, M.; Oumi, Y.; Tanaka, S. Solvent/OSDA-free interzeolite transformation of FAU into CHA zeolite with quantitative yield. Microporous Mesoporous Mater. 2019, 278, 219-224. [CrossRef] 
48. da Silva, A.D.; Livotto, P.R.; dos Santos, J.H.Z. Hybrid silica as cues for understanding the role of water in dry zeolite synthesis. Appl. Surf. Sci. 2020, 508, 145305. [CrossRef]

49. Fickel, D.W.; Fedeyko, J.M.; Lobo, R.F. Copper Coordination in Cu-SSZ-13 and Cu-SSZ-16 Investigated by Variable-Temperature XRD. J. Phys. Chem. C 2010, 114, 1633-1640. [CrossRef]

50. Kim, G.J.; Ahn, W.S. Direct Synthesis and Characterization of High-Sio2-Content Mordenites. Zeolites 1991, 11, 745-750. [CrossRef]

51. Zhang, J.J.; Lu, X.F.; Wang, Z.B. Control of crystallization rate and morphology of zeolite silicalite- 1 in solvent-free synthesis. Microporous Mesoporous Mater. 2019, 283, 14-24. [CrossRef]

52. Wang, Y.Q.; Duan, H.C.; Tan, Z.G.; Meng, X.J.; Xiao, F.S. Illuminating solvent-free synthesis of zeolites. Dalton Trans. 2020, 49, 6939-6944. [CrossRef]

53. Derouane, E.G.; Vedrine, J.C.; Pinto, R.R.; Borges, P.M.; Costa, L.; Lemos, M.A.N.D.A.; Lemos, F.; Ribeiro, F.R. The Acidity of Zeolites: Concepts, Measurements and Relation to Catalysis: A Review on Experimental and Theoretical Methods for the Study of Zeolite Acidity. Catal. Rev. 2013, 55, 454-515. [CrossRef] 